\title{
Revision of the early Middle Pleistocene bears (Ursidae, Mammalia) of Central Europe, with special respect to possible co-occurrence of spelaeoid and arctoid lineages
}

\author{
JAN WAGNER \& STANISLAV ČERMÁK
}

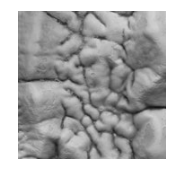

\begin{abstract}
The bears from the Late Biharian localities Koněprusy Caves, C 718 and Kozi Grzbiet differ significantly from $U$. arctos, particularly in morphology of metaconid and entoconid complex of $\mathrm{m} 1$. In contrast, they exhibit a number of dental morphometric characters typical for spelaeoid lineage for which we interpret them as the early members of $U$. deningeri clade. Also the nominal taxa U. suessenbornensis, U. etruscus gombaszogensis and $U$. savini are assigned to spelaeoid lineage. $U$. sackdillingensis is tentatively assigned to arctoid lineage, similarly as few single specimens from Late Biharian sites Chlum 4, Kövesvárad, Přezletice and Voigtstedt. All other material from these sites was identified as $U$. deningeri. A smaller part of the studied material, including the type series of $U$. eberbachensis, is of ambiguous taxonomical status and do not allow an exact species determination. $\bullet$ Key words: Ursus deningeri, U. arctos, Late Biharian, Early Toringian, Middle Pleistocene.
\end{abstract}

WAGNER, J. \& ČERMÁK, S. 2012. Revision of the early Middle Pleistocene bears (Ursidae, Mammalia) of Central Europe, with special respect to possible co-occurrence of spelaeoid and arctoid lineages. Bulletin of Geosciences 87(3), 461-496 (12 figures, 3 appendices). Czech Geological Survey, Prague. ISSN 1214-1119. Manuscript received March 19, 2012; accepted in revised form May 15, 2012; published online September 19, 2012; issued September 28, 2012.

Jan Wagner (corresponding author), Department of Paleontology, National Museum, Cirkusová 1740, 19300 Praha 9 HorníPočernice, Czech Republic; jan_wagner@nm.cz,wagnerj@gli.cas.cz•Stanislav Čermák, Institute of Geology, Academy of Science of the Czech Republic,v.v.i., Rozvojová 269, 16500 Praha 6, Czech Republic; cermaks@ gli.cas.cz

The evolutionary history of spelaeoid bear is a traditional theme within fossil mammal research in Europe (e.g. Reichenau 1904, 1906; Freudenberg 1914; Ehrenberg 1928; Rode 1935). Although main interest was concerned to the Late Pleistocene bears, there are many studies dealing with earlier representatives of this lineage, mostly focused on the Toringian $U$. deningeri Reichenau, 1904 (e.g. Kurtén 1955a, 1959; Schütt 1968; Argant 1980, 1991; Bishop 1982; Torres 1988a, b; Torres \& Cervera 1995; Musil 1991). New detailed studies further confirm the presence of Toringian spelaeoid bears in Asia (e.g. Tchernov \& Tsoukala 1997, Baryshnikov \& Foronova 2001, Baryshnikov \& Kalmykov 2005, Sher et al. 2011) as well as existence of deeply divergent lineage of spelaeoid bears in Caucasus and Siberia (e.g. Baryshnikov 1998, Knapp et al. 2009). Moreover new excavation yielded an important material of late Early Pleistocene ursids (Moullé 1992, García \& Arsuaga 2001, Musil 2001, García 2003, Madurell-Malapeira et al. 2009) with possible affinity to spelaeoid bears. All these new discoveries have demanded a radical reevaluation of traditional mo- dels on evolution of spelaeoid bears, refining the set of diagnostic characters, patterns of their variation and phylogenetic meaning, including establishing reliable autapomorphic characters discriminating the arctoid and spelaeoid lineages.

Yet, a new reevalution of cave bear evolutionary history is complicated by absence of reliable information about spelaeoid bears from the crucial period of the Late Biharian, the earliest period of the Middle Pleistocene. Until now, only few data were published (e.g. Kurtén 1969, Musil 1974, Wiszniowska 1989). Moreover, due to the lack of detailed information, several isolated specimens were described as new taxa (e.g. Soergel 1926, Kretzoi 1938) of uncertain affinity. The present paper, summarizing the results of revision of vast majority of dental material available from Central Europe (462 specimens), is thus intended to (1) define a morphometric characteristic of the Late Biharian U. deningeri, (2) critically evaluate the taxonomic status of bear taxa described from this period and (3) re-examine possible occurrence of arctoid bears during the early Middle Pleistocene. 


\section{Material and methods}

\section{Material}

The cheek teeth material used in the study includes: (a) 64 individuals of extant $U$. arctos Linnaeus, 1758, (b) 320 specimens from three Late Biharian localities belonging to $U$. deningeri, (c) 142 specimens from 7 localities which taxonomical status is uncertain and (d) 12 individuals of extant $U$. thibetanus Cuvier, 1823 (Primorje region, Russia; ZIN). All morphometrical data refer to values collected by authors if not specified differently. Metrical data for Middle Pleistocene brown bears (Heppenloch, Grays Thurrock and Ehringsdorf) are taken from Kurtén (1959, 1975).

(a) The respective material of extant $U$. arctos includes the following subsamples according to their geographic origin:

(ai) Balkan subsample (abal), bears mostly from Croatia ( $N=28$, most of them deposited in ZUVM, with few ones from the private owners), with single specimens from Bulgaria, Rumania (both housed in NHMW), northern Greece (deposited in AUT) and Austria (NHMW; it represents an immigrant from the Balkan peninsula);

(aii) Siberia subsample (asib), specimens from Siberia $(\mathrm{N}=8)$, Primorje Region of the Russian Far East $(\mathrm{N}=4)$ and from Sachalin $(\mathrm{N}=1)$, all housed in ZIN with the exception of one specimen from Primorje Region deposited in NHMW;

(aiii) Tibet subsample (atib), bears of Tibet subspecies U. a. pruinosus Blyth, $1854(\mathrm{~N}=6 ; \mathrm{ZIN})$;

(aiv) Kamchatka subsample (akam), bears from Kamchatka peninsula, belonging to the subspecies $U$. a. piscator Pucheran, 1855 ( $\mathrm{N}=12$; NHMW);

(av) The complete $U$. arctos sample (aall), composed of the above mentioned subsamples and 3 additional specimens from Central Asia (U. a. isabellinus Horsfield, 1827; ZIN).

(b) The extensive samples of bears from three Late Biharian, more precisely OIS 17-19, localities supposedly asigned to $U$. deningeri (dall): (bi) cave C718 (dfc); (bii) Koněprusy Caves (dkc) (both in the Czech Republic; deposited in NMP) and (biii) Kozi Grzbiet (dkg) (Poland; deposited in ISEA).

(c) The bears from localities listed below were included into our analysis without a priori taxonomical determination. They include the material from type localities (incl. type series) of various nominal taxa or the assemblages supposedly composed of more than one bear species.

(ci) Kövesvárad (Hungary) (kovA, kovB)

Age: Late Biharian (Fejfar \& Heinrich 1983), OIS 17.

Jánossy (1963) described 2 bear species from this locality, classical $U$. deningeri and small U. mediterraneus Major, 1873 (based on one P4 dex., inv. No. V.63/252). All material from this locality is deposited in HNHM. We divided this material into two units, sp. A (kovA) containing assumed $U$. deningeri and sp. B (kovB) containing P4 determined as $U$. mediterraneus and one extraordinary small $\mathrm{m} 3$ dex. (V.63/203f).

(cii) Chlum 1, 4 (Czech Republic) (chA, chB)

Age: Late Biharian, OIS 19 (Fejfar 1964, Horáček \& Ložek 1988).

The faunal assemblages from lowermost level of these two neighbouring karst fissures are of the same stratigraphical age (Horáček 1979). Wagner (2004) determined two bear species in this faunal assemblage: $U$. deningeri and $U$. t. mediterraneus. We divided this material into two units, sp. A (chA) containing assumed $U$. deningeri and sp. B (chB) containing two extraordinary small molars (m1 sin.: Ra 2147, $\mathrm{m} 2$ dex.: Ra 2148). The material is housed in NMP.

(ciii) Gombasek (= Gombaszög; Slovakia) (gom)

Age: probably Late Biharian (Fejfar \& Heinrich 1983); the age of this old collection is mostly based on co-identification with the Late Biharian fauna newly collected from the same quarry by Fejfar (1956), but this co-identification is not unambiguous and the old collection can be also older (Horáček \& Ložek 1988).

Type locality of U. etruscus gombaszogensis Kretzoi, 1938. We included in the analysis the type series (holotype: $\mathrm{m} 2$ dex., V.59/930) as well as the specimens from the same collection that were not included into the type series by Kretzoi (deposited in HNHM). We have not included the later collected specimens (e.g. by O. Fejfar).

(civ) Süßenborn (Germany) (sue)

Age: Late Biharian (Fejfar 1969, Heinrich 1990), OIS 17; this stratigraphical determination, based on newly excavated arvicolid material, is valid for so called Hauptfauna of Süßenborn; the exact stratigraphical position of older collections is uncertain.

Type locality of U. suessenbornensis Soergel, 1926. We included in the analysis all bear teeth from this locality (incl. lectotype: M1 dex., 1965/2425; deposited in SFQW). Both type specimens are somewhat damaged. We used for the metric characteristic (Appendix 2, Tables 4, 6) only their unambiguously measurable measurements, but we applied approximate values for some subsequent analysis. We took over the maximal length for $\mathrm{m} 2$ dex. (1965/2423) and maximal length, buccal length of anterior lobe and Pa-length for M1 dex. (1965/2425) from Soergel (1926). The values from Soergel are similar to ours estimations and are the least spelaeoid in comparison to other published data (see Kurtén 1969, Baryshnikov 2007).

(cv) Eberbach (Germany) (ebe)

Age: unknown.

Type locality of $U$. eberbachensis Heller, 1939. All four available molars (syntypes) were included in the analysis (deposited in SMNK). 
(cvi) Sackdilling (= Windloch bei Sackdilling; Germany) (sac)

Age: Late Biharian (Fejfar \& Heinrich 1983), latest Early Pleistocene (predate Brunhes/Matuyama boundary) (Maul et al. 2007).

Type locality of $U$. sackdillingensis Heller, 1955. One tooth is available from this locality (holotype: M2 dex., Hsa 117, UEN).

Institutional abbreviations. - AUT - Aristotle University of Thessaloniki, Thessaloniki, Greece; HNHM - Hungarian Natural History Museum, Budapest, Hungary; ISEA Institute of Systematics and Evolution of Animals PAN, Krakow, Poland; NHM - Natural History Museum, London, Great Britain; NHMW - Naturhistorisches Museum, Wien, Austria; NMP - National Museum, Prague, Czech Republic; SFQW - Senckenberg - Forschungsstation für Quartärpaläontologie, Weimar, Germany; SMNK - Staatliches Museum für Naturkunde, Karlsruhe, Germany; UEN - Friedrich-Alexander-Universität Erlangen-Nürnberg, Erlangen, Germany; ZIN - Zoological Institute RAS, St. Petersburg, Russia; ZUVM - Zagreb University, Faculty of Veterinary Medicine, Zagreb, Croatia.

\section{Methods}

All the specimens were measured, photographed and databased. The measurements were taken and expressed with aid of engineering calipers with $0.1 \mathrm{~mm}$ accuracy. The specimens figured were covered by a thin film of $\mathrm{NH}_{4} \mathrm{Cl}$ before making photos, if permitted by curator, and enhanced using Adobe Photoshop CS4 software.

The teeth measurements are defined according to Rode (1935). The exception is buccal length of anterior and posterior lobe of $\mathrm{M} 1$, which is taken from the $\mathrm{Me} / \mathrm{Pa}$ boundary to the end of parastyle and metastyle respectively with the tips of caliper jaws touching the landmarks (in contrary to Rode (1935) where this parameter is taken parallel to the tooth axis). The lingual length of $\mathrm{P} 4$ is defined according to Baryshnikov (1998, 2007; the character No. 4 in P4). We measured both right and left tooth row in recent specimens of $U$. arctos, if available, but only one of them in recent $U$. thibetanus.

The terminology and abbreviations of teeth morphology structures is adopted from Rabeder (1983, 1989, 1999). The term $\mathrm{x}$-conid/con refers strictly to a cusp itself, while a term $\mathrm{X}$-conid/con-complex denotes the cusp with its secondary structures (small cusps, swellings etc.). In p4, the term linguo-distal crest refers to the crest separating from the protoconid top or its distal arm (respectively from the crest connecting protoconid with distal end of the tooth/hypoconid) and continuing distally or linguo-distally. We call the structures with visible tip as cusps and the structures without tip as swellings. See Appendix 1 for definitions of morphotypes. For m3 we used term buccal constriction for Rabeder's (1999) "buccale Einbuchtung" and distal convexity for Rabeder's “distale Ausbuchtung”. The non metrical characters were scored using $(0,1,2,3,4)$ scale.

We computed a set of basic statistic for each sample and we applied some multivariate techniques for comparative purpose. We used means values for both metric and morphological characters for each (sub)sample for cluster analysis (unweighed pair-group average, 1-Pearson-r). The factor analysis was used for studying the dependency of particular characters in $U$. arctos and U. deningeri. General discriminant analysis and one-way ANOVA were used for detecting the significance of discrimination between $U$. arctos and $U$. deningeri. Mann-Whitney $\mathrm{U}$ Test was used for confirmation of this significance. Principle component analysis, one-way ANOVA and factor analysis were used for analyzing the position of specimens with uncertain taxonomic status. All computation and graphs were prepared by Excel and StatSoft-Statistica 6.

Capital and lowercase letters, I/i (incisors), C/c (canines), $\mathrm{P} / \mathrm{p}$ (premolars), and $\mathrm{M} / \mathrm{m}$ (molars), refer to upper and lower permanent teeth, respectively. We used " $\mathrm{N}$ " for number of individuals for the recent and minimum number of individuals for the fossil record respectively and " $n$ " for number of the specimens. The term "arctoid" means "similar to our sample of $U$. arctos", term "deningeroid" means "similar to our sample of Early Biharian U. deningeri", term "spelaeoid" means "bearing characters supposedly typical for spelaeoid lineage".

The definition and subdivision of the Quaternary period follow Gibbard \& Cohen (2008) and Gibbard \& Head (2009a, b). The definition and subdivision of the Mammal Ages (i.e. Biharian and Toringian) follows Fejfar \& Heinrich $(1983,1990)$ and Fejfar et al. (1998).

\section{Results}

The samples of $U$. arctos and $U$. deningeri were proven as homogenous and significantly distinctive from each other for all tooth types (see below for details). The morphometric characteristic of the particular samples are summarized in electronic Appendix 2 (Tables 1-7), including the results of morphotype frequency analysis (Tables 8,9 ) - available online on www.geology.cz/bulletin. The results of discrimination analysis for $U$. arctos and $U$. deningeri, including the standardized coefficients of canonical discriminant function for each tooth type are given in Appendix 3 (Table 1), further supported with respective confirmation statistics (Mann-Whitney U Test: $z, p$ ) for particular tooth types (Table 2). The Appendix 3 provides also results of multivariate analyses of the morphometric characteristics of particular samples (Fig. 1). The details concerning particular dental elements are surveyed below. 


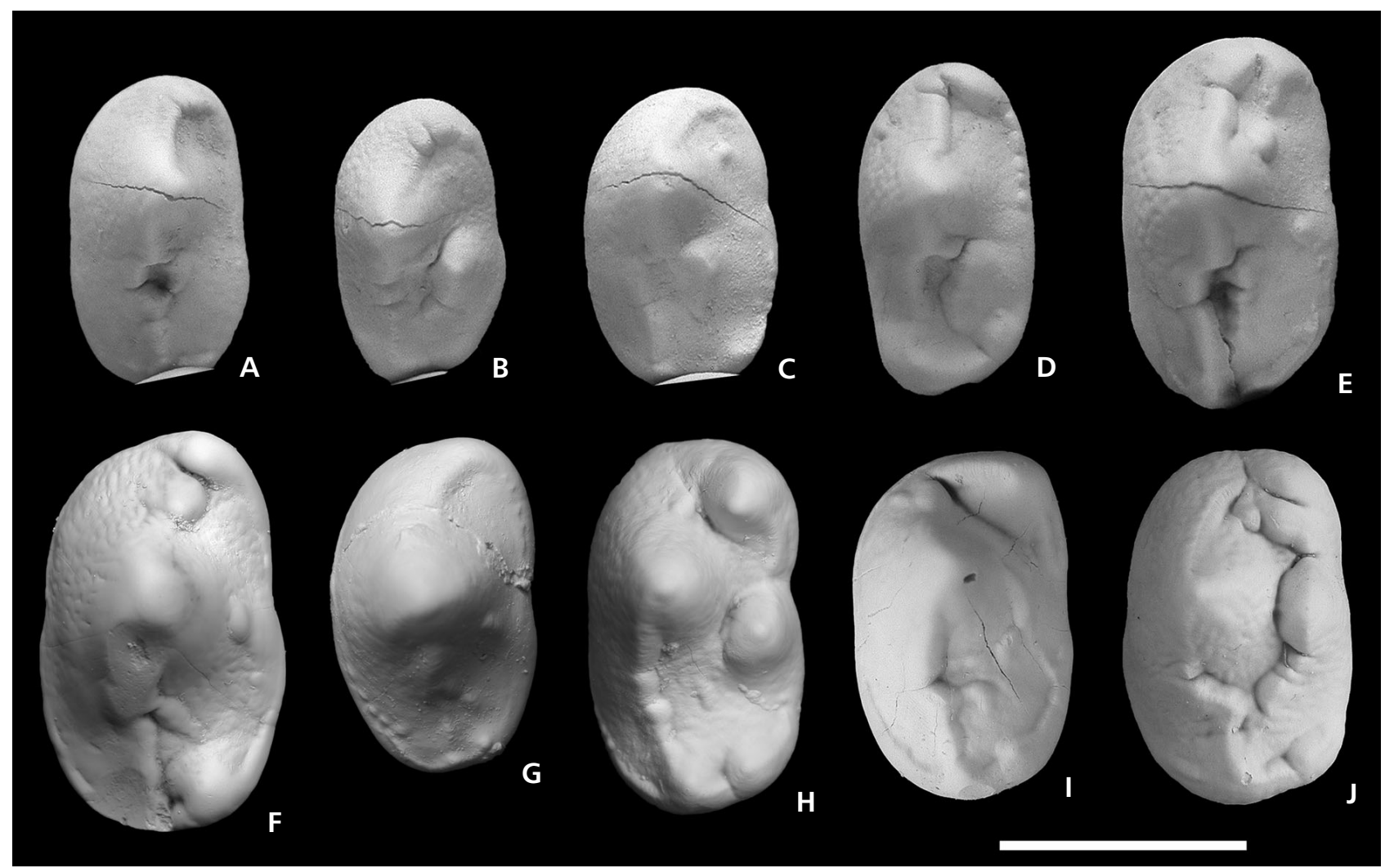

Figure 1. Occlusal view of selected specimens of $\mathrm{p} 4 \mathrm{inf}$. from studied samples. $-\mathrm{A}-\mathrm{E}-U$. arctos; A - Siberia (6161), B - Siberia (15071), C - Primorje (21662), D - Tibet (6216), E - Tibet (7802). • F-J - U. deningeri; F - C718 (Rv 20003), G - Koněprusy Caves (Rv 20004), H - Koněprusy Caves (Rv 20005), I - Kozi Grzbiet (MF/1346/47), J - Kozi Grzbiet (MF/1346/28). All teeth are figured as left specimens (B, C, F, G, I and J reversed). Scale bar: $10 \mathrm{~mm}$.

p4 inf. (Fig. 1). Based on the studied sample/characters, p4 shows the lowest capability to discriminate $U$. arctos from $U$. deningeri. Both, maximal length and maximal width are almost the same for both species with only slightly higher average and maximum for $U$. deningeri. The maximal width/maximal length ratio is almost identical for both samples. The canonical discriminant function discriminates only $62.3 \%$ of specimens $(p<0.001)$. The most important characters are both morphological ones (but they are significantly correlated together based on the factor analysis). Important difference is in the succession of paraconid/metaconid emerging. Paraconid occurs prior metaconid in $U$. deningeri (in $U$. arctos the sequence is reversed) and is able to reach more robust stage in this species than in $U$. arctos. If bears from Kövesvárad, sp. A and Gombasek are included to the analysis, the most significant sorting $(\mathrm{F}=16.6, \mathrm{p}<0.001$; one-way ANOVA) divides the bears into two samples, $U$. arctos and $U$. deningeri together with bears from Kövesvárad and Gombasek, grouping supported also by PCA (Fig. 2A).

$\mathrm{m} 1$ inf. (Fig. 3). Both species differ in both metrical and morphological characters. The teeth are smaller (but see discussion) and relatively broader (Fig. 4A) in
U. arctos. The most apparent morphological differences concern entoconid- and metaconid-complex diversification. The End-c is usually composed from large dominant End1 and obviously smaller End2 with a short mesial arm in $U$. arctos. In $U$. deningeri, End-complex forms usually gradually descending crest with End2 bearing longer mesial arm, often further diversified (Fig. 4B). These differences lead also to significant differences in End2-c-length between both species. Mesostylid can be present in both species. Concerning metaconid-complex, the arrangement with mesial metastylid turning medially from metaconid is more characteristic for $U$. deningeri. In $U$. arctos, mesial metastylid usually continues mesially or even slightly laterally from metaconid. The canonical discriminant function discriminates $94.7 \%$ of specimens $(\mathrm{p}<0.001)$. The most important characters are morphological characters chIII-V, lingual length of talonid, End2-c-length and index End2-c-length/End1-c-length. Factor analysis shows similar general pattern of characters correlation in both, $U$. arctos and U. deningeri. Most of length and width parameters are correlated together with the exception of End1-c- and End2-c-length (the latter correlated with $\mathrm{chV}$ ) that are independent. The other group of correlated characters is formed by most of indexes 

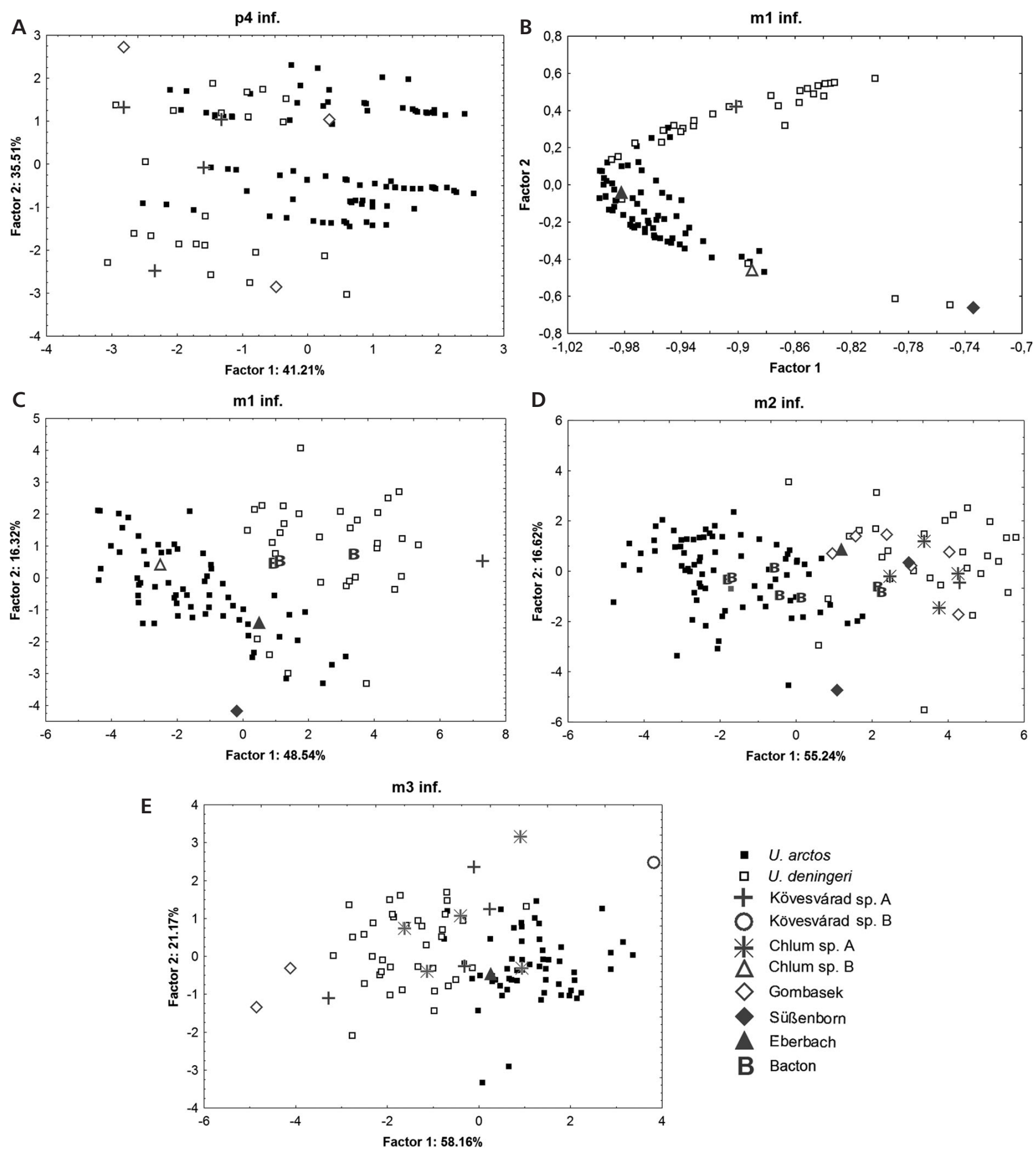

- U. arctos

U. deningeri

+ Kövesvárad sp. A

O Kövesvárad sp. B

찻 Chlum sp. A

$\triangle$ Chlum sp. B

$\diamond$ Gombasek

Süßenborn

$\triangle$ Eberbach

B Bacton

Figure 2. Graphical results of PCA for first and second principal component (A, C-E) and of factor analysis (B). • A - p4 inf., B, C - m1 inf., $\mathrm{D}-\mathrm{m} 2$ inf., $\mathrm{E}-\mathrm{m} 3$ inf.

and morphological characters. Cluster analysis (Appendix 3, Fig. 1A) shows affinity of Eberbach to $U$. arctos, Süßenborn and Chlum, sp. B are placed as outgroups to both, $U$. arctos and $U$. deningeri. The one-way ANOVA gives value $\mathrm{F}=32(\mathrm{p}<0.001)$ if only $U$. arctos and $U$. deningeri are analyzed. By including Ursus spp. from other studied localities, the most significant sorting $(\mathrm{F}=31, \mathrm{p}<0.001)$ unites $U$. arctos and Chlum, sp. B in one sample and $U$. deningeri with the rest specimens (incl. Süßenborn and Eberbach) in the other (if $U$. arctos is united with Chlum, sp. B and Eberbach, F = 30). All the sorting with more than two units have $\mathrm{F}<10$. Factor 
analysis, using chIII, End1-c- and End2-c-length and PC1 (calculated from all other length and width characters), shows (Fig. 2B) clearly differences between $U$. arctos and $U$. deningeri as well as separated position of the teeth without End2 (3 specimens in the right lower corner; see discussion for details). Similar distribution is given also by principal component analysis (Fig. 2C, graph for metrical characters and indexes only), but the specimens without End2 are placed among U. arctos. Both analysis placed Eberabach and Chlum, sp. B into $U$. arctos-group.

$\mathrm{m} 2$ inf. (Fig. 5). The teeth are smaller (but see discussion) and relatively broader (Fig. 4C) in $U$. arctos than in $U$. deningeri. $U$. deningeri differs morphologically from $U$. arctos especially in (a) more often and more strongly developed central constriction and (b) more diversified inner field of tooth crown. The latter is demonstrated, e.g. by higher frequency of more diversified mesolophid or metalophid. The canonical discriminant function discriminates $90.1 \%$ of specimens $(\mathrm{p}<0.001)$. None of characters was marked as significantly important. Factor analysis shows no correlation among End1- and End2-length and maximal length for both species. Cluster analysis of all characters (Appendix 3, Fig. 1B) placed Süßenborn, Gombasek and Balkan subsample of $U$. arctos among $U$. deningeri (see discusion for details) and Eberbach and Chlum, sp. B as outgroups to both $U$. arctos and $U$. deningeri. If only metric characters and indexes are used (Appendix 3, Fig. 1C), Chlum, sp. B clusters with $U$. arctos and Süßenborn and Gombasek with $U$. deningeri, Eberbach stays as outgroup. The one-way ANOVA gives value $\mathrm{F}=$ $15.9(\mathrm{p}<0.001)$ if only $U$. arctos and $U$. deningeri are analyzed. The most significant sorting $(\mathrm{F}=19.4, \mathrm{p}<0.001)$ was given for uniting $U$. arctos with Chlum, sp. B and Eberbach and $U$. deningeri with Kövesvárad, sp. A, Chlum, sp. A, Gombasek and Süßenborn (if Eberbach is replaced to $U$. deningeri, $\mathrm{F}=17.9$ ). All the sortings with more than two units have $\mathrm{F}<10$. Principal component analysis (Fig. 2D; graph for metrical characters and indexes only) places Chlum, sp. $\mathrm{B}$ among $U$. arctos and Eberbach on the boundary of $U$. arctos and $U$. deningeri. Few specimens of $U$. deningeri (and one from Süßenborn) bear an arctoid position (see discussion for details).

$\mathrm{m} 3$ inf. (Fig. 6). The teeth of $U$. deningeri are in average larger than those in $U$. arctos. The opposite tendency in length-width correlation (Fig. 4D) than in both previous molars is recognized in $\mathrm{m} 3$ ( $U$. deningeri relatively broader than in $U$. arctos). There is more intensive tendency to increasing the complexity of occlusal surface and the tooth outline in $U$. deningeri than in $U$. arctos. In $U$. arctos, the tooth outline is usually without any or with only incipient interruption. The canonical discriminant function discriminates $88.8 \%$ of specimens $(\mathrm{p}<0.001)$. The most important characters are both morphological characters. If morphological characters are excluded from the analysis (the morphological characters are often invisible due to the stage of wear and their exclusion therefore importantly increases the number of analyzed specimens), the canonical discriminant function discriminates $86.1 \%$ of specimens $(\mathrm{p}<0.001$; the most important characters is maximal length). The one-way ANOVA gives value $\mathrm{F}=36.6(\mathrm{p}<0.001)$ if only $U$. arctos and $U$. deningeri are analyzed. The most significant sorting $(\mathrm{F}=34.0, \mathrm{p}<0.001)$ was given for uniting $U$. arctos with Eberbach and $U$. deningeri with Kövesvárad, sp. A, sp. B and Chlum, sp. A (if Kövesvárad, sp. B is replaced to $U$. arctos, $\mathrm{F}=33.3$ ). Principal component analysis (Fig. 2E; graph for metrical characters and indexes only) places Eberbach in $U$. arctos near the boundary with $U$. deningeri. Kövesvárad, sp. B shows an isolated position. One specimen of $U$. deningeri and one of Chlum, sp. A are placed among $U$. arctos.

P4 sup. (Fig. 7). The overlap between $U$. deningeri and $U$. arctos is relatively large in all observed morphometric characters. The most important discriminative character is the shape of buccal wall with more frequent and more developed constriction in $U$. deningeri. There is a great overlap in maximal length and somewhat better discriminative ability of maximal width ( $c f$. Fig. 8A) can be only misleading effect of low number of $U$. arctos specimens (moreover, with dominance of small ones). The species also do not differ principally in stage of diversification of mains cusps. The only exception, but with weak discriminative ability, can be a tendency to larger metastylids in $U$. deningeri ( $c f$. Fig. $8 \mathrm{~B}$ ). The canonical discriminant function discriminates $84.9 \%$ of specimens $(\mathrm{p}<0.001)$. The most important characters are maximal width and index maximal width/maximal length. If maximal width is excluded from the analysis (due to its position in maxilla, it is not possible to take maximal width of $\mathrm{P} 4$ in many specimens of recent $U$. arctos), the canonical discriminant function discriminates $76.6 \%$ of specimens ( $p<0.001$; the most important characters are width of constriction, chI and index width of constriction/lingual length). Two latter characters are correlated according to factor analysis. This analysis shows further the correlation among width of constriction, maximal width and lingual length and between Me-length and maximal length for both species. Cluster analysis of all characters (Appendix 3, Fig. 1D) placed Gombasek among $U$. deningeri and Kövesvárad, sp. B as outgroup to both $U$. arctos and $U$. deningeri. The one-way ANOVA (for the dataset without maximal width) gives value $\mathrm{F}=14.2$ $(\mathrm{p}<0.001)$ if only $U$. arctos and $U$. deningeri are analyzed. The most significant sorting $(\mathrm{F}=17.2, \mathrm{p}<0.001)$ was given for uniting $U$. arctos with Kövesvárad, sp. B and $U$. deningeri with Chlum, sp. A and Gombasek. Principal component analysis (Fig. 9A; graph for non-morphological data without maximal width) places Kövesvárad, sp. B 


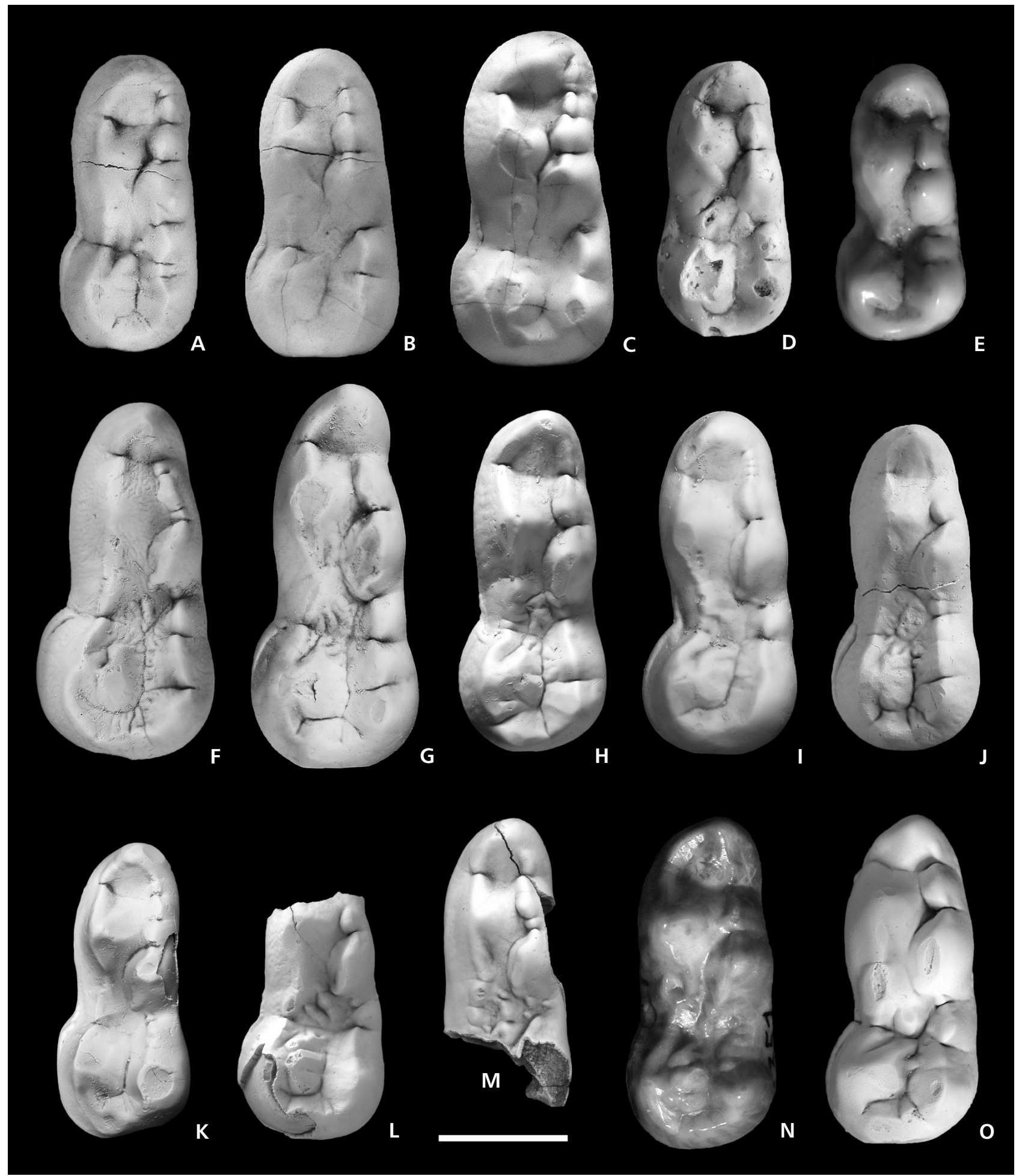

Figure 3. Occlusal view of selected specimens of $\mathrm{m} 1$ inf. from studied samples. $\bullet A-E-U$. arctos; A - Siberia (13880), B - Primorje (21663), C - Tibet (7683), D - Greece (AUT), E - Croatia (privat collection). • F-J - U. deningeri; F - C718 (Rv 20006), G - C718 (Rv 20007), H - Koněprusy Caves (Rv 20008), I - Koněprusy Caves (Rv 20009), J - Kozi Grzbiet (MF/1346/8). K-O - Ursus sp.; K - Chlum, sp. B (Ra 2147), L - Gombasek (V.59/969), M - Gombasek (V.25/1023a), N - Süßenborn (1965/2426), O - Eberbach (M.3743). All teeth are figured as left specimens (A, B, D-F, H, J, M and O reversed). Scale bar: $10 \mathrm{~mm}$. 

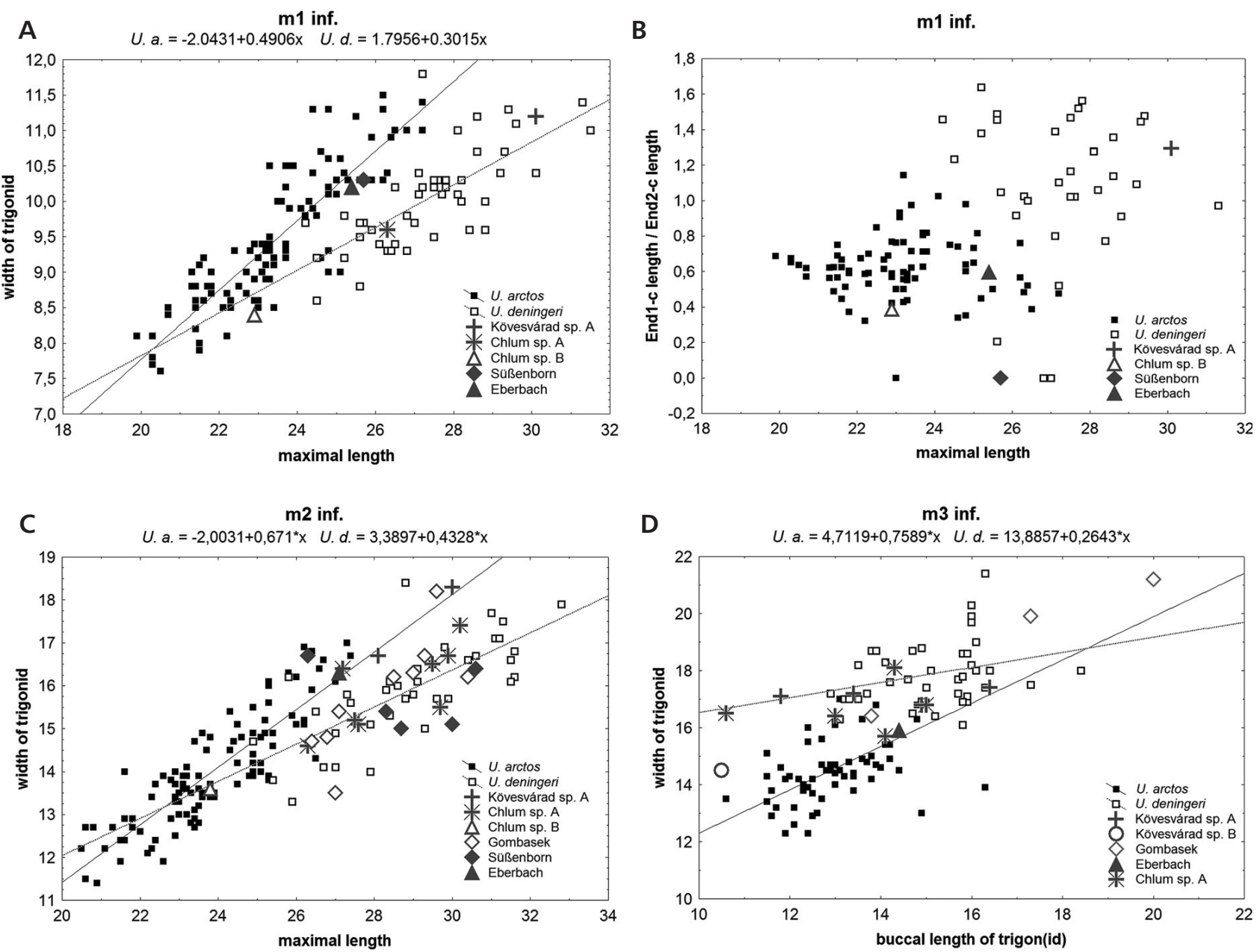

Figure 4. Scatter plots for selected variables of lower cheek teeth. $\bullet A, B-m 1$ inf., C - m2 inf., D-m3 inf.

among $U$. arctos. One specimen of $U$. deningeri is placed among $U$. arctos.

M1 sup. (Fig. 10). Except the size (but see discussion), $U$. arctos and $U$. deningeri differ in relatively breadth of central constriction in larger specimens, but in the smaller ones the ratio inclines to be more similar for both species (Fig. 8C). Ursus deningeri differs from U. arctos also in (a) higher frequency and stronger development of lingual constriction and (b) predominating the specimens with metastyl larger than parastly (oppositely in $U$. arctos). The canonical discriminant function discriminates $84.3 \%$ of specimens $(\mathrm{p}<0.001$; the most important characters are chII and length of anterior lobe). The results are almost identical if chI is excluded. Factor analysis shows the general correlation for all length and width characters for both species (although it differs in details between species). Very significant is correlation among the widths, among lengths the correlation between maximal length and length of $\mathrm{Pa} / \mathrm{Me}$ is weaker than between maximal length and length of anterior/posterior lobe. The width/length indexes are also strongly correlated. Cluster analysis (Appendix 3,
Fig. 1E) placed Gombasek, Süßenborn and Eberbach among $U$. deningeri. The one-way ANOVA (for complete dataset) gives value $\mathrm{F}=15(\mathrm{p}<0.001)$ if only $U$. arctos and $U$. deningeri are analyzed. If the chI is excluded (it allows to include the lectotype of $U$. suessenbornensis into the analysis), $\mathrm{F}=16$. The most significant sorting $(\mathrm{F}=16$, $\mathrm{p}<0.001$ ) was given for $U$. arctos as separate unit and uniting of $U$. deningeri with Kövesvárad, sp. A, Chlum, sp. A, Gombasek, Süßenborn, Eberbach (if Eberbach or Gombasek are united with $U$. arctos, $\mathrm{F}=15$; if Süßenborn is united with $U$. arctos, $\mathrm{F}=14$ ). Principal component analysis (Fig. 9B; graph for data without chI) places lectotype of $U$. suessenbornensis among $U$. deningeri.

M2 sup. (Fig. 11). U. deningeri is larger and somewhat relatively broader compared to $U$. arctos, if posterior width is used (Fig. 8D). The situation would be reversed, if anterior width was used. Talon length extends more in $U$. deningeri but with large overlap between both species. The occlusal surface is more diversified in U. deningeri, as apparent from higher percentage of specimens with strongly developed metaloph, posthypocon and metastyl. 


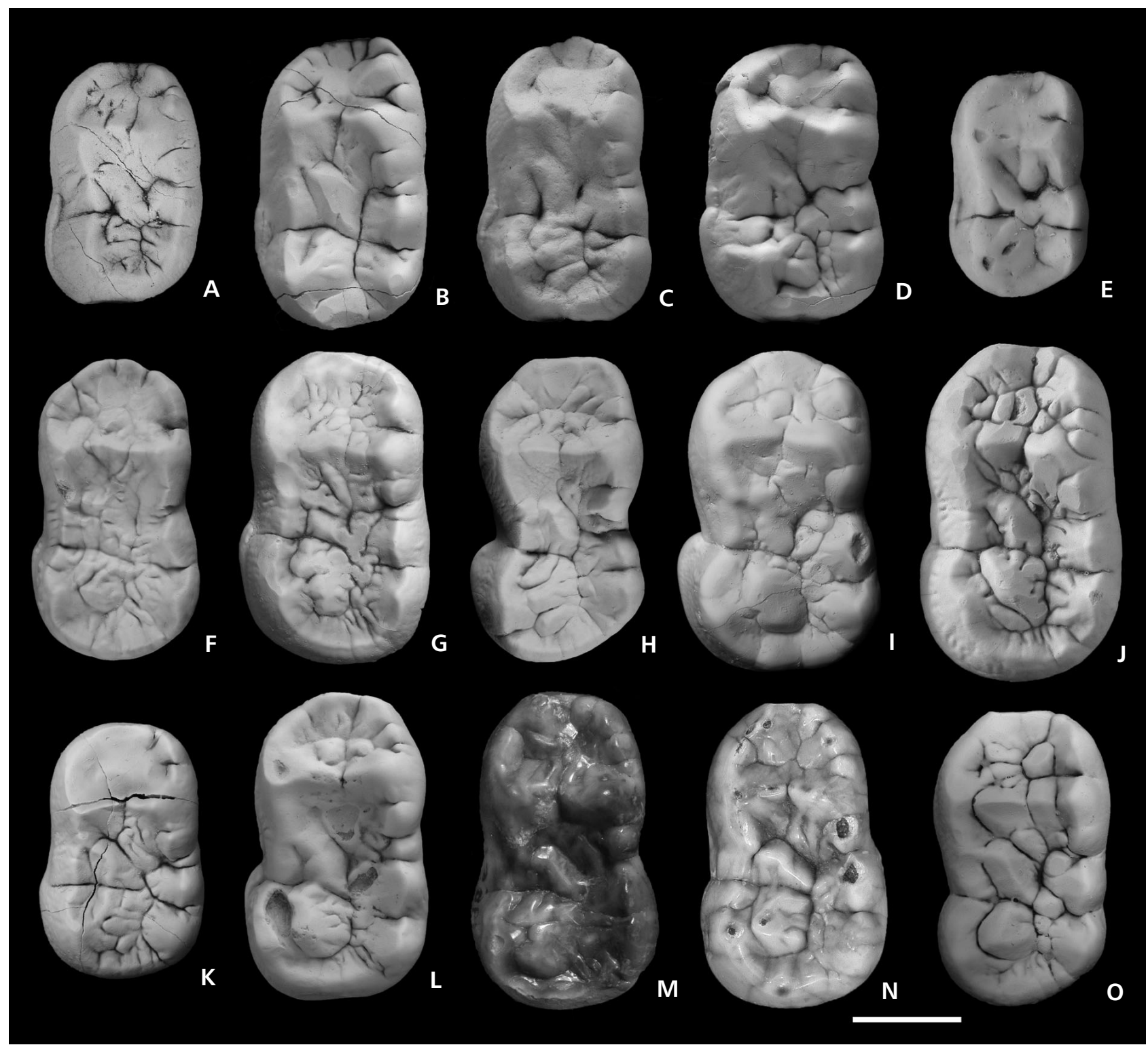

Figure 5. Occlusal view of selected specimens of $\mathrm{m} 2$ inf. from studied samples. - A-E - U. arctos; A - Siberia (13880), B - Sachalin (29162), C - Primorje (15149), D - Tibet (7809), E - Greece (AUT). • F-J - U. deningeri; F - C718 (Ra 129), G - C718 (R 9740), H - Koněprusy Caves (Rv 20010), I - Koněprusy Caves (Rv 20011), J - Kozi Grzbiet (MF/1346/37). K-O - Ursus sp.; K - Chlum, sp. B (Ra 2148), L - Gombasek (V.59/930), M - Süßenborn (1965/2423), N - Süßenborn (1965/1307), O - Eberbach (M.3745). All teeth are figured as left specimens (C-E, H-M and O reversed). Scale bar: $10 \mathrm{~mm}$.

The canonical discriminant function discriminates $92.8 \%$ of specimens $(\mathrm{p}<0.001$; most important characters is chIII) if all the dataset is used and $92.1 \%$ of specimens ( $\mathrm{p}<0.001$; most important characters are chIII and width of posterior lobe) if Me- and Pa-length (and the connected indexes) are excluded (that allow to include more specimens into the analysis). Cluster analysis (Appendix 3, Fig. 1F; for dataset without chII and Me-length) placed Gombasek among $U$. deningeri and Sackdilling and Süßenborn as outgroups to both $U$. arctos and $U$. deningeri. The one-way ANOVA (for complete data set) gives value $\mathrm{F}=13.8(\mathrm{p}<0.001)$ if only $U$. arctos and $U$. deningeri are analyzed. If the $\mathrm{Me}-$ and $\mathrm{Pa}-$ length and the connected indexes are excluded, $\mathrm{F}=22$. The most significant sorting (for such a reduced dataset) was calculated $(\mathrm{F}=21, \mathrm{p}<0.001)$ for $U$. arctos united with Sackdilling and $U$. deningeri $i$ with Kövesvárad, sp. A, Chlum, sp. A and Gombasek (if Sackdilling is united with $U$. deningeri, $\mathrm{F}=19$ ). Principal component analysis (Fig. 9C; graph for data without chII, Me- and Pa-length and the connected indexes) places Süßenborn among $U$. deningeri and Sackdilling among $U$. arctos. 


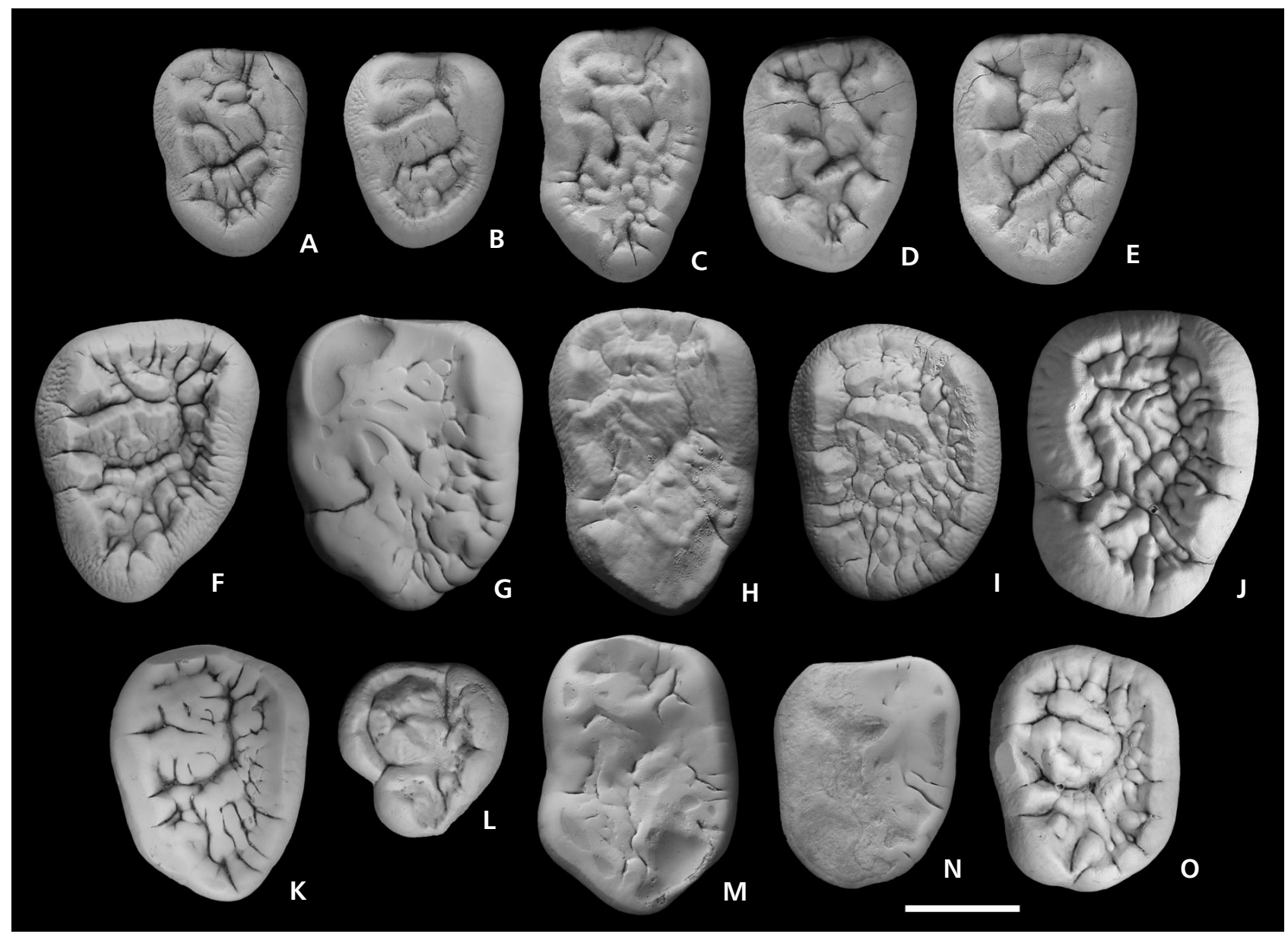

Figure 6. Occlusal view of selected specimens of $\mathrm{m} 3$ inf. from studied samples. - A-E - U. arctos; A - Siberia (13880), B - Siberia (13881), C - Primorje (15149), D - Tibet (6216), E - Tibet (7802). • F-J - U. deningeri; F - C718 (Rv 20012), G - C718 (Rv 20013), H - Koněprusy Caves (Rv 20014), I - Koněprusy Caves (Rv 20015), J - Kozi Grzbiet (MF/1346/45). • K-O - Ursus sp.; K - Kövesvárad, sp. A (V.63/203b), L - Kövesvárad, sp. B (V.63/203f), M - Gombasek (V.59/1010a), N- Gombasek (V.59/1010b), O - Eberbach (M.3745). All teeth are figured as left specimens (B, C, F, $\mathrm{K}, \mathrm{L}$ and $\mathrm{O}$ reversed). Scale bar: $10 \mathrm{~mm}$.

\section{Discussion and conclusions}

As a primary motivation of this study was to reexamine real possibilities of discrimination of the Late Biharian $U$. arctos- $U$. deningeri based on dental characters. Naturally, we focused first to the characters that were reported as discriminative for $U$. arctos- $U$. spelaeus in former studies. Unfortunately, it was not always possible to score the state of these characters completely. The particular cases were as follows: (a) Kurtén (1955a) demonstrated significant differences of relative paracon height in M1 between $U$. arctos and $U$. spelaeus. Nevertheless, there was, especially in our $U$. arctos sample, high percentage of worn teeth that do not allow us to pursue this character in present study. The same applies for other high measurements (e.g. relation of End1- and End2-height in m1). (b) It was proven (e.g. Rode 1935) that the tooth crown is more open in $U$. spelaeus than in $U$. arctos. This is especially apparent in paraconid of $\mathrm{m} 1$ or metastyl and parastyle of M1. We were not able to quantify this character and therefore we did not include it in our analysis. Nevertheless, we can confirm that, in general, the crowns are somewhat more opened in Late Biharian $U$. deningeri than in recent $U$. arctos. (c) With the latter character is also connected gradually increasing of occlusal surface diversification in cheek teeth ( $c f$. Rabeder 1999). Although we can prove the differences in occlusal surface diversification between $U$. deningeri and recent $U$. arctos, we were able, due to the stage of wear in many recent brown bear teeth, to study these differences only in very limited number of characters. But we see it as a very promising possibility for future research. Concerning all morphological characters, it is necessary to note that their particular states are only descriptive and do not constitute a phyletic lineage.

We used only the recent representatives of $U$. arctos for comparative purposes to have the certainty of monospecifity of the sample. But it is necessary to note that the used sample of $U$. arctos does not cover all the variability 


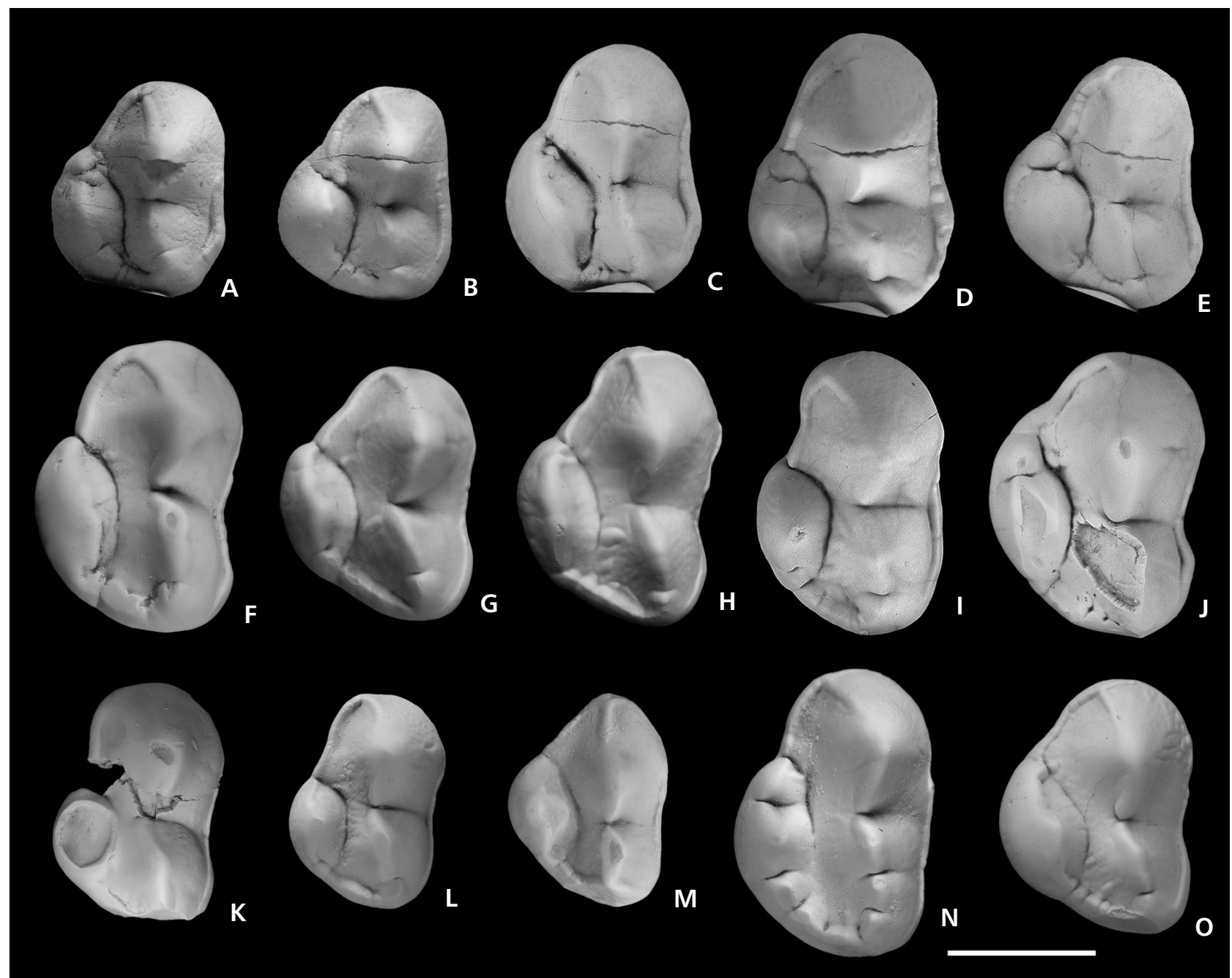

Figure 7. Occlusal view of selected specimens of P4 sup. from studied samples. - A-E - U. arctos; A - Siberia (13881), B - Siberia (15071), C - Primorje (21663), D - Tibet (7802), E - Tibet (7807). • F-J - U. deningeri; F - C718 (Rv 20016), G - Koněprusy Caves (Rv 20017), H - Koněprusy Caves (Rv 20018), I - Kozi Grzbiet (MF/1346/28), J - Kozi Grzbiet (MF/1346/31). • K-O - Ursus sp.; K - Kövesvárad, sp. A (V.63/195a), L - Kövesvárad, sp. B (V.63/252), M - U. thibetanus, Kudaro 1 (36301), N - Chlum, sp. A (Ra 2409), O - Gombasek (V.59/1061). All teeth are figured as left specimens (B, C, F, G, I, L and M reversed). Scale bar: $10 \mathrm{~mm}$.

known for the Weichselian and Eemian brown bears, especially concerning the maximal values of their metric characters. Similarly, the exceeding values occur ( $c f$. Kurtén 1955a, 1959, 1975) also in the middle and late Middle Pleistocene brown bears (but their taxonomical status needs a new critical revision). In any case, the overlap between $U$. arctos and Late Biharian $U$. deningeri will increase if these Middle and Late Pleistocene forms are included in the comparison. Therefore we do not have discussed here the brown bear specimens placed by the analysis among $U$. deningeri. It is worth to note that in the cluster analysis (Appendix 3, Fig. 1B, C) of all characters of $\mathrm{m} 2$, the sample from Balkan peninsula appears among $U$. deningeri. Obviously, it responds to a higher frequency of morphological characters usually occurring in $U$. deningeri. It is interesting that simi- lar tendency occurs also in other teeth (brown bears from Croatia represent the smallest teeth among studied subsamples). On the other hand, Kurtén (op. cit.) shows that Middle and Late Pleistocene brown bears are relatively similar in their morphological characters and proportion to the recent ones.

Concerning $U$. deningeri sample, we did not take in account an influence of possible differences in sex ratio in different localities. Nevertheless the sexual dimorphism in the cheek teeth size in ursids is ambiguous ( $c f$. Kurtén 1955b, Grandal 2001, Baryshnikov et al. 2003, Miller et al. 2009 etc.) and can be omitted. For obvious reasons, our samples do not allow to filter out effects of paleoclimatic context (glacial/interglacial), yet we suppose that for the present purpose (i.e. interspecific discrimination) this factor might not play any significant role. 

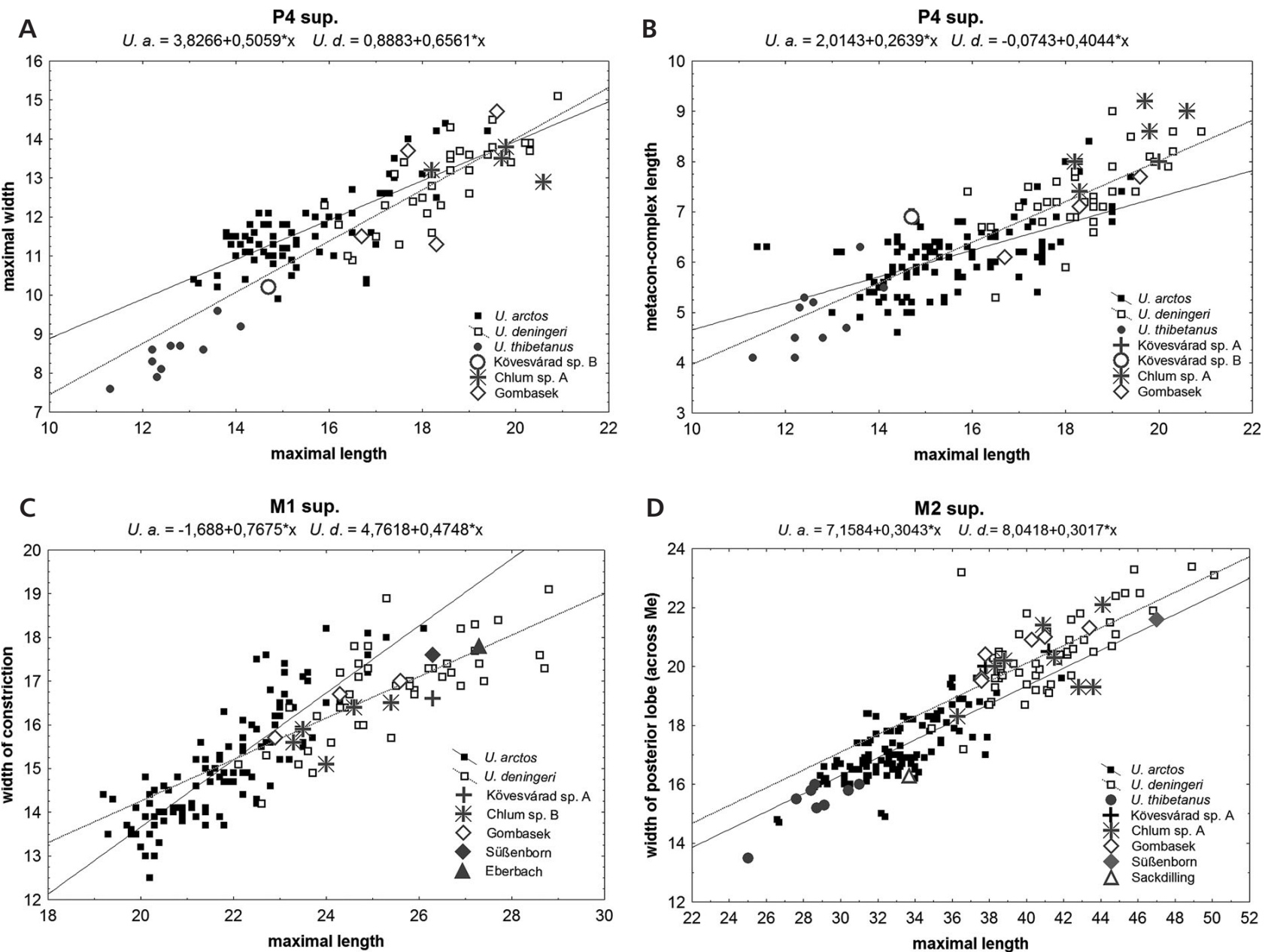

Figure 8. Scatter plots for selected variables of upper cheek teeth. • A, B - P4 sup., C - M1 sup., D - M2 sup.

\section{Characteristic of Late Biharian U. deningeri in Central Europe}

The basic patterns of character variation can be revealed in the samples which are sufficiently rich in representation of particular dental elements and are well defined in the stratigraphical respect. Such demands are entirely responded by the samples of bear asemblages from the cave C718, Koněprusy Caves and Kozi Grzbiet. The assemblages were found monospecific (except for two specimens from Kozi Grbiet) and were determined as $U$. deningeri also by previous studies (Wiszniowska 1989; Wagner 2004, 2005a). All these assemblages represent, most probably, the rests of hibernacula (in all localities milk teeth and neonate bones were found), sometimes probably partly redeposited. The cave C718 probably represented an entrance facies of such a bear cave. All three localities are of the Late Biharian age (Fejfar \& Heinrich 1983, Fejfar et al. 2004, Horáček \& Ložek 1988, Nadachowski 1985 and in verb.), cave C718 and Kozi Grzbiet represent OIS 17 (although a few specimens could originate from preceeding glacial; see references above), the Koněprusy Caves represent either OIS 17 or OIS 19.

We assume a similar taphonomy as in the Late Pleistocene bear caves, where all or almost all bear material belongs to the cave bear. Therefore we attribute a priori all the bear teeth from these localities to $U$. deningeri. The only exceptions are 2 specimens from Kozi Grzbiet (M2 sin., MF/1346/36 and M1 dex., MF/1346/10, both ISEA) that we excluded from the analysis due to their large size and highly diversified occlusal surface (i.e. affinity to U. spelaeus) and somewhat different fossilization. But it is possible that these specimens represent only the extreme morphotypes of Late Biharian $U$. deningeri. But even in this case, the analysis would not be affected by their exclusion. Taxonomic status of some other problematic specimens (with arctoid affinity) will be discussed below.

As concerns, the dental specificities characterizing these samples, the following is particularly worth of mentioning: (1) All p4 inf. are relatively small and often simply built. There are specimens with no other cusps than Prd as well as specimens with well developed Pad and Med. They 

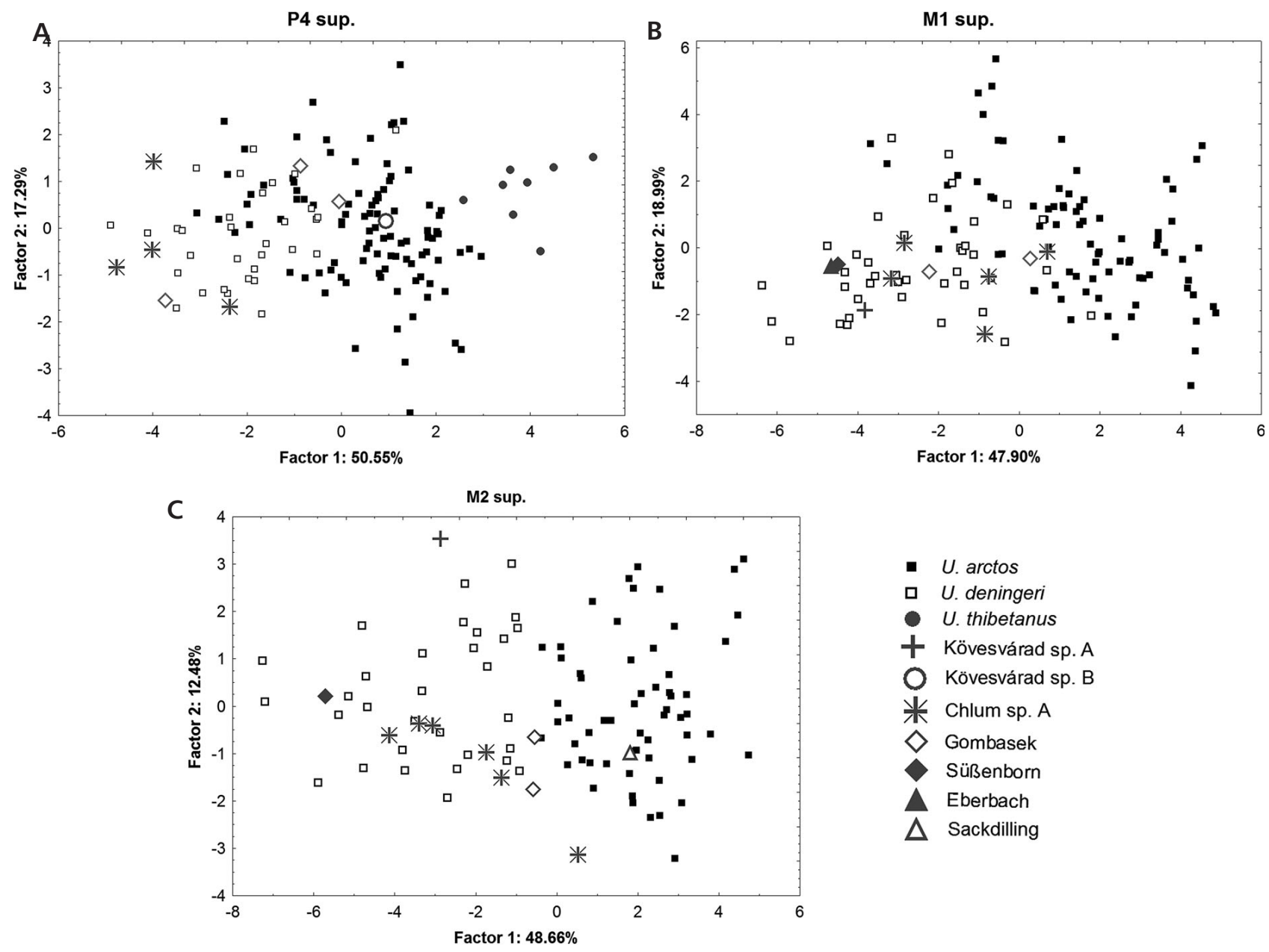

Figure 9. Graphical results of PCA for first and second principal component. • A - P4 sup., B - M1 sup., C - M2 sup.

have arrangement typical for spelaeoid lineage, i.e. Pad is more prominent than Med (see also Rabeder 1983, 1989). For spelaeoid bears it is typical if (a) only Pad is present, (b) Pad is more strongly developed than Med or (c) Pad and Med are both very strong cusps. For $U$. arctos it is typical if (a) only Med is present or (b) Med is evidently stronger than Pad. In $U$. arctos Med is also often placed distally from Prd and/or connected with linguo-distal crest. In few specimens from Tibet (e.g. Fig. 1E), the Med is weaker than Pad (which is good apparent but not strong) and placed considerably distally. In teeth without Pad and Med or if both of them are present as weakly developed cusps, it is not possible to distinguished between $U$. deningeri and $U$. arctos with certainty. All the studied specimens bear indeterminative or spelaeoid arrangement.

(2) In accord with previous opinions (cf.e.g. Qiu et al. 2009), $\mathrm{m} 1$ is the element most significan for taxonomic purposes. In this tooth, we regard the differentiation of lingual main cusps as the most important taxonomical character. The ancestral stage for representatives of genus Ursus is the presence of entoconid 1 and metaconid without any mesial structures. There is a strong evolutionary tendency in most ursine lineage to fill the space between End1 and Med and Med and Pad by newly developed enamel structures (crests, swellings, cusps). According to our opinion, in each bear lineage this problem was solved independently and (mostly) uniquely (of course, with respect to the stage in their ancestor). Med-c is relatively little diversified in studied sample. The space between Med and Prd is in the most cases filled only partly, in several cases there is only a small swelling in front of Med and all the space is fully open (more often in specimens from Koněprusy cave than in C 718). In recent $U$. arctos, the space is filled more completely (often fully). From this point of view the recent $U$. arctos is more evolved than the Late Biharian $U$. deningeri. Still more important are differences in general shape of Med-c. But it is necessary to note that both afterwards discussed arrangements occur in both species but in significantly different frequency. Type I: The mesial metastylids turn medially in respect to Med-axis. The buccal wall of trigonid is usually bulged around the Med/metystylid boundary. This type dominates in Late Biharian 


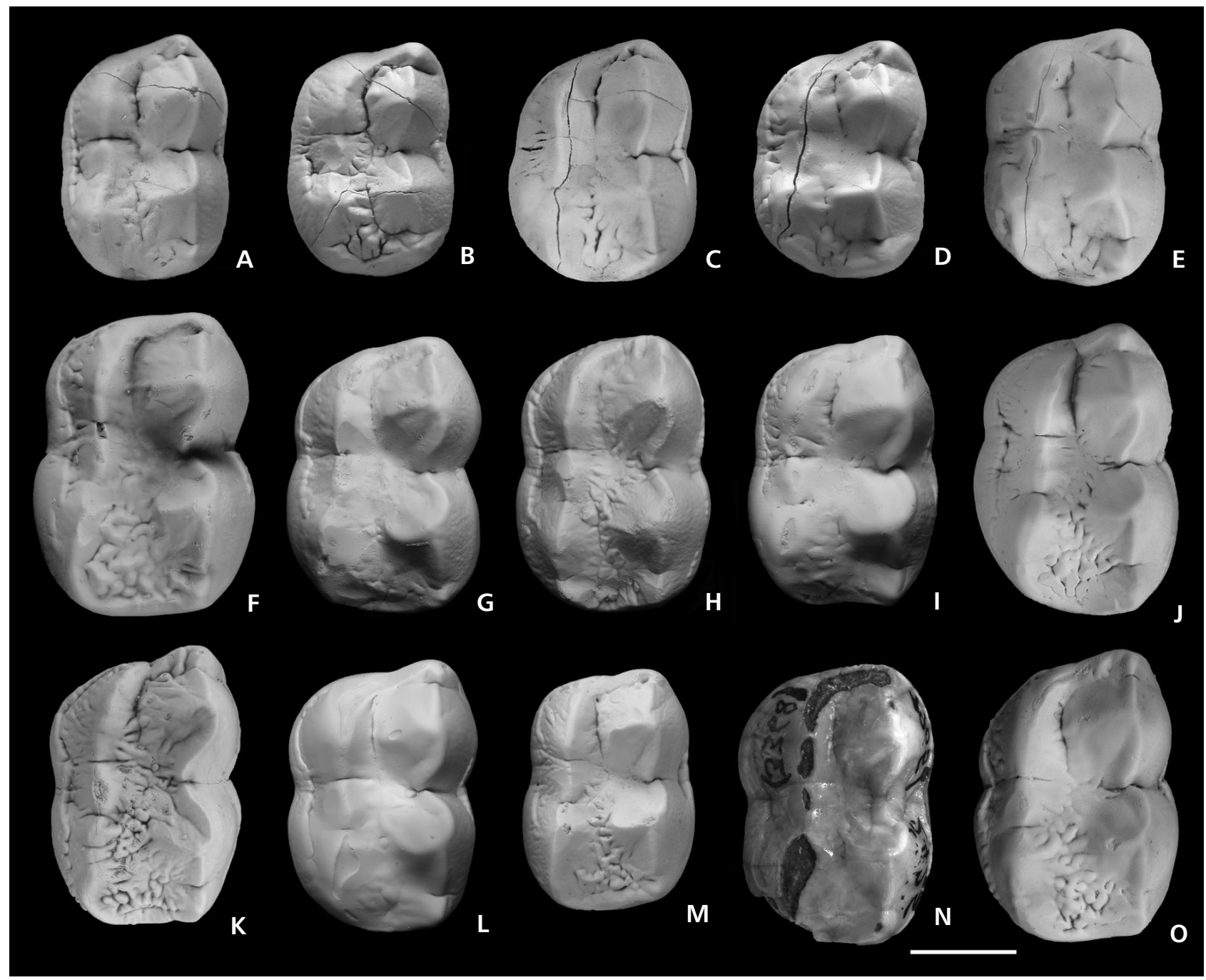

Figure 10. Occlusal view of selected specimens of M1 sup. from studied samples. • A-E - U. arctos; A - Jakutia (27229), B - Siberia (15071), C - Primorje (21663), D - Tibet (6216), E - Tibet (7809). - F-J - U. deningeri; F - C718 (Rv 20019), G - C718 (Ra 114), H - Koněprusy Caves (Rv 20020), I - Koněprusy Caves (Rv 20021), J - Kozi Grzbiet (MF/1346/38). K-O - Ursus sp.; K - Kövesvárad, sp. A (V.63/196a), L - Chlum, sp. A (Ra2407), M - Gombasek (V.59/1019a), N - Süßenborn (1965/2425), O - Eberbach (M.3744). All teeth are figured as left specimens (B, D, F, I, K, L, N and $\mathrm{O}$ reversed). Scale bar: $10 \mathrm{~mm}$.

$U$. deningeri as well as in other studied samples of U. deningeri (Jagsthausen, Mosbach 2, Hundsheim, Petralona). Type II: The mesial metastylids tend to continue mesially or mesio-laterally, there is no apparent bulging of buccal wall. This type dominates in recent $U$. arctos and was present also in teeth from Eemian locality Chlupáčova sluj (Czech Republic, n=3; NMP). We therefore conclude, that the differences in Med-c between spelaeoid and arctoid lineage can not be reduced easily to number of metastylids and represent probably two alternative strategies for infilling the space between Med and Pad. It seems that these two different shapes of Med-c are also connected with different shape of Prd. It is therefore, alternatively, possible that ascertained differences in frequency of these morphotypes reflect differences in form of Prd. The Prd connected with type I usually has (a) distal arm less medialwardly turned and (b) more laterally extended medial slope. The Prd connected with type II usually has (a) distal arm more medialwardly turned (plesiomorphic character) and (b) the whole Prd body mesially shifted. Also more opened crown in spelaeoid bears can play some role. But in general it is problematic to decide what is the causation and what is the consequence. Based on the photos in Musil (2001) it seems that bears from Untermaßfeld have rather the type II. On the other hand, several specimens of $U$. etruscus from Olivola and Upper Valdarno and especially from Erpfingerhöhle show type I.

The other important character in $\mathrm{m} 1$ is the stage of entoconid-complex development. The main differences were described in Results (see also Appendix 2, Table 8). 


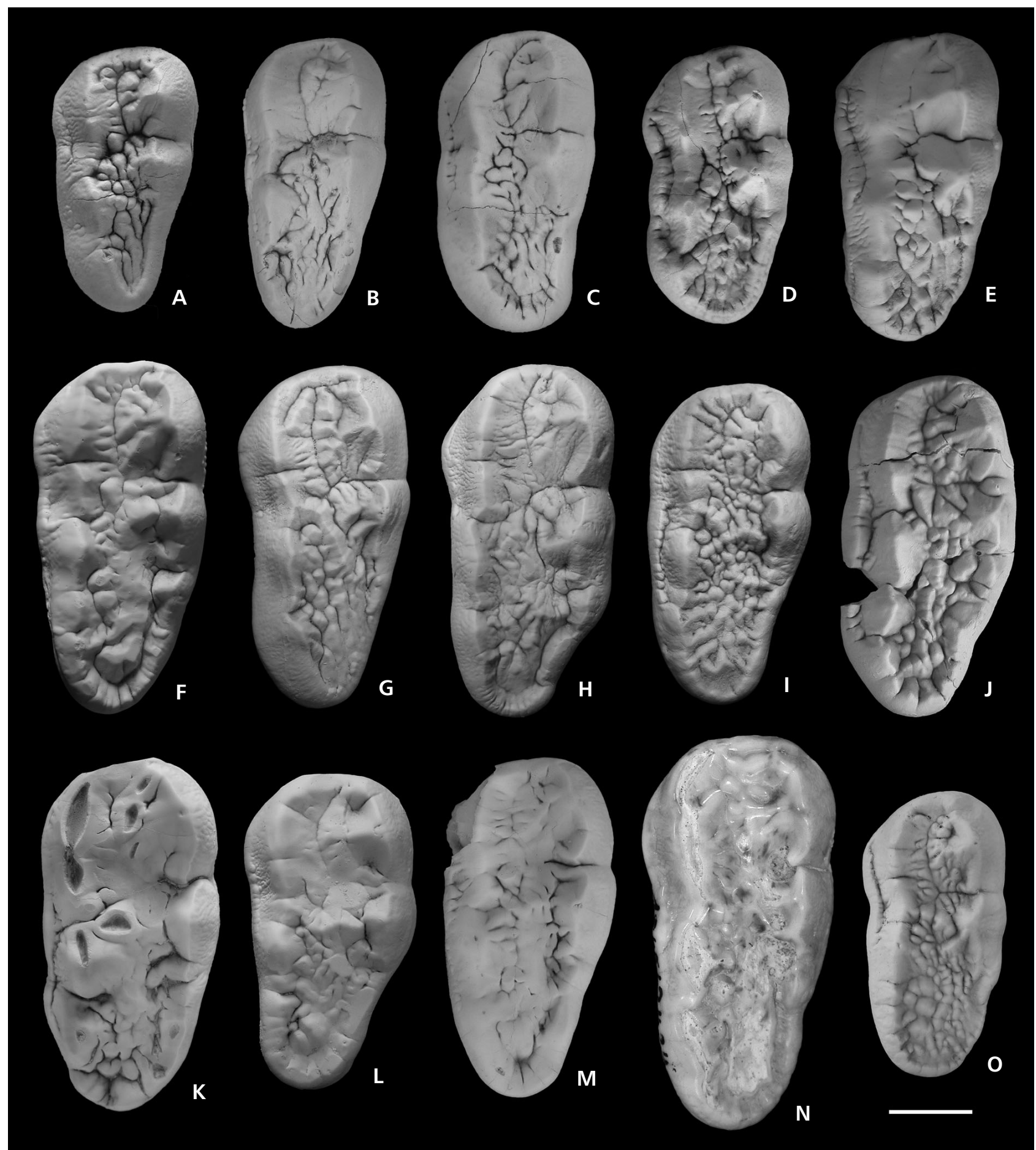

Figure 11. Occlusal view of selected specimens of M2 sup. from studied samples. • A-E - U. arctos; A - Siberia (15071), B - Jakutia (27229), C-Primorje (21663), D - Tibet (6216), E - Tibet (7805). F-J - U. deningeri; F-C718 (Ra 151), G - C718 (Ra 119), H - Koněprusy Caves (Rv 20022), I - Koněprusy Caves (Rv 20023), J - Kozi Grzbiet (MF/1346/11). K-O - Ursus sp.; K - Kövesvárad, sp. A (V.63/197a), L - Gombasek (V.59/1065a), M - Gombasek (V.59/961), N - Süßenborn (1965/2424), O - Sackdilling (Hsa 117). All teeth are figured as left specimens (B, F, G, H and O reversed). Scale bar: $10 \mathrm{~mm}$.

End2 was missing or only slightly incipient in few specimens of Late Biharian U. deningeri (see below), stage not noticed in recent $U$. arctos sample. That is further evidence for the assumption that recent $U$. arctos is more evolved than the early Middle Pleistocene $U$. deningeri. Similar to Med-c, we supposed that the different arrangements of 
End-c represent rather two alternative ways for infilling the space between End1 and Med than two subsequent evolutionary stages. This assumption must be still confirm by revision of large-size Eemian and Weichselian U. arctos, where more space for pre-End1structures can be expected. The important finding of our analysis is also the independency of End1-c- and End2-c-length to the maximal length in $\mathrm{m} 1$ and $\mathrm{m} 2$ (for both $U$. arctos and $U$. deningeri). We can deduce that tooth is divided into several independent compartments which development/diversification is only weakly interconnected. This is probably the model valid for all the cheek teeth. The similar model is documented by Rabeder (1999), who analyses in detail the diversification of particular elements in U. spelaeus teeth.

(3) All the teeth (except p4) are generally larger than those in the comparative sample of $U$. arctos. But the published average values of maximal length of Eemian and Weichselian U. arctos (Rode 1935, Musil 1964) are very similar to those of our sample of $U$. deningeri. The differences in proportions are more important. Rode (1935) shows that $U$. arctos has relatively broader teeth (with exception of $\mathrm{p} 4$ and $\mathrm{m} 3$ ) than $U$. spelaeus. The same situation is apparent also in the Late Biharian U. deningeri. p4 is approximately of the same relative width as $U$. arctos (U. spelaeus has relatively broader $\mathrm{p} 4$ (Rode 1935) as a result of its molarisation) and $\mathrm{m} 3$ is relatively broader in our sample of $U$. deningeri (Fig. 4D). M2 is relatively narrower if compared anterior width (across $\mathrm{Pa}$ ) and relatively broader if compared the posterior width (across Me) in U. deningeri (Fig. 8D). But the latter can be only the result of local specificity of bears from C718 and Koněprusy Caves (see also Wagner 2005b). The smaller relative width in spelaeoid bears is an interesting phenomenon. It goes against the general evolutionary trend of increasing the cheek teeth occlusal surface in this lineage. Probably, there are several constrains forbid/complicate the independent changes in the length and width in spelaeoid lineage. In this case, this ratio could be a heritage of the ancestor. The same could be valid also for the arctoid lineage. But we only have very limited knowledge about pre-Eemian brown bears. It is also worth to note that there is a large overlap in this character and therefore only a comparison of average values of larger samples is relevant. We can see also some tendency to an increase in the relatively width of $\mathrm{m} 1$ and especially $\mathrm{m} 2$ in spelaeoid lineage (see section about Bacton).

(4) Most of the teeth (in both morphological and metrical aspect) of Late Biharian $U$. deningeri already express characters typical for spelaeoid lineage. The only exceptions are some characters in M1 - relative width of central constriction (even opposite trend than in U. spelaeus), relation of anterior and posterior lobe width and, partly, the stage of development of parastyle and metastyl. In these characters the Late Biharian $U$. deningeri shares the simi- larity rather with $U$. arctos than the later spelaeoid bears (Rode 1935, see also Wagner 2005b, appendix D). We suppose that this tooth is most conservative and shares lots of plesiomorphic characters. The similarity with the recent brown bear can be a result of presence of the same plesiomorphies or the parallelism.

(5) Concerning presence of anterior premolars, we have only limited jaw material (all originate from cave C718). There is no anterior premolar present in 4 mandibular fragments (but in some cases the most messial part of distama is missing/damaged, so sporadic occurence of $\mathrm{p} 1$ is not possible to exclude). One small rostral fragment includes both right and left maxilla. There are present alveoli of P3.

(6) In most of tooth types, there are several specimens that are placed among $U$. arctos, separately from other $U$. deningeri. Exceptions are $\mathrm{p} 4$ and $\mathrm{M} 1$, where the strongest overlap is present and no $U$. deningeri tooth is obviously separate from the others. Four specimens of $\mathrm{m} 1$ are placed among $U$. arctos in Fig. 2C. Two of them (Rv 20028, Rv 20009, NMP; Fig. 3I) form a separated group together with specimens from Süßenborn in Fig. 2B. They are characterised by absence of End2, similarly, the m1 sin. (Rv 20025; NMP; Fig. 12B) has a very small End2 (to distinct between very small End2 and well developed mesostylid is problematic in some specimens). All these specimens are fully deningeroid (from both metrical and morphological view) and we assign them to U. deningeri. In the latter (Rv 20024, NMP; Fig. 12A), the situation is more problematic. It bears also a relatively small End2, but moreover its general form is relatively broader than usually in other teeth. Its Med and Pad have arrangement more usually in $U$. deningeri. The tooth is relatively large (maximal length $27.2 \mathrm{~mm}$ ). We assign it to Ursus sp., although we see its affiliation with $U$. deningeri more probable. Three small $\mathrm{m} 1$ (maximal length under $25.0 \mathrm{~mm}$ ) in our sample have deningeroid morphology, one of them is in the mandibular fragment without any anterior premolars.

Three specimens of $\mathrm{m} 2$ have rather arctoid position in the Fig. 2D (the right lower quadrant). The uppermost one (Kozi Grzbiet, MF/1346/1, ISEA) belongs, according to us, to $U$. deningeri. Its border position can be caused by combination of somewhat smaller size and relatively simply built inner field of the tooth. But its general form is deningeroid. The lowermost one (Kozi Grzbiet, MF/1346/2, ISEA; Fig. 12D) has very closed crown, the character absent in all other specimens of $U$. deningeri. On the other hand, this tooth is relatively large (maximal length $28.8 \mathrm{~mm}$ ). The middle one (C718, Ra 156, NMP; Fig. 12C) is rather small (in respect to other U. deningeri; maximal length $25.8 \mathrm{~mm}$ ) and very broad. It differs in its length-width ratio from all other $U$. deningeri. But its relative width exceeds even that of $U$. arctos and seems to be rather abnormal. The last problematic tooth (not included in PCA due to its damage) is $\mathrm{m} 2 \mathrm{sin}$. from Koněprusy Caves 


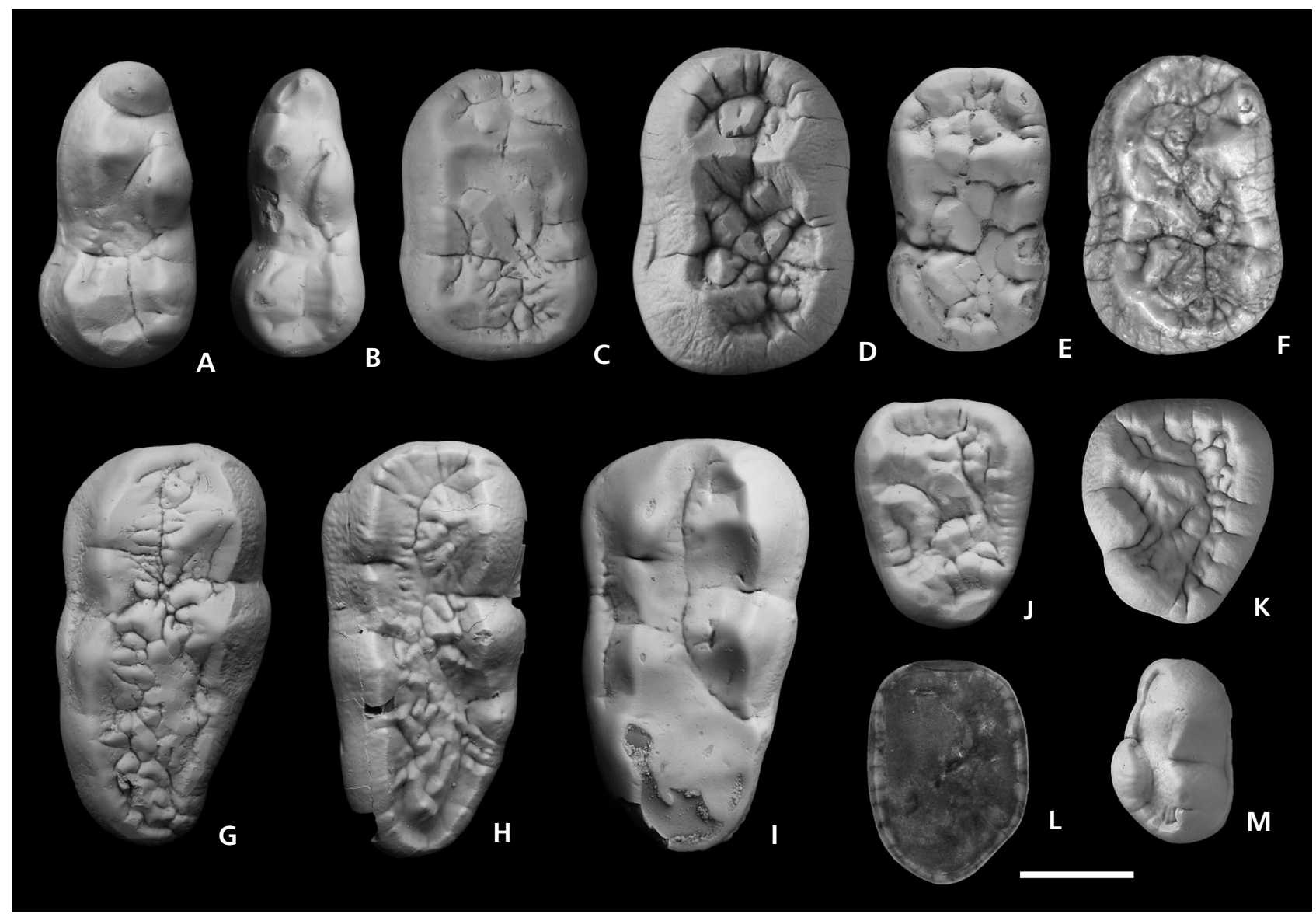

Figure 12. Occlusal view of selected specimens with ambiguous taxonomic affinity. • A - m1, C718 (Rv 20024), B - m1, Koněprusy Caves (Rv 20025), C - m2, C718 (Ra 156), D - m2, Kozi Grzbiet (MF/1346/2), E - m2, Koněprusy Caves (Rv 20026), F - m2, Süßenborn (1965/2422), G - M2, C718 (Ra 117), H - M2, C718 (Rv 20027), I - M2, Chlum (R 2042), J - m3, Chlum (Ra 2416), K - m3, Kozi Grzbiet (MF/1346/16), L - m3, Voigtstedt (1966/7751), M - P4, Kozi Grzbiet (MF/1346/14). All teeth are figured as left specimens (A, C, G, H and K reversed). Scale bar: $10 \mathrm{~mm}$.

(Rv 20026, NMP; Fig. 12E) representing the smallest tooth in the $U$. deningeri sample (maximal length $24.9 \mathrm{~mm}$ ). If the available characters are analyzed, this tooth is placed among $U$. arctos but near the boundary with $U$. deningeri. Its general morphology is rather deningeroid and its position among brown bears is probably caused by its small size. We assign all three latter discussed teeth to Ursus sp., but their affinity to $U$. deningeri is probable according to us. None of them express the combination of characters typical for $U$. arctos. None of these teeth was placed near the specimen of Chlum, sp. B.

One, relatively small (maximal length $20.0 \mathrm{~mm}$ ) m3 (Kozi Grzbiet, MF/1346/16, ISEA; Fig. 12K) was placed among $U$. arctos. But its morphology is rather deningeroid, i.e. it bears well present buccal constriction, well developed hypoconid and weak distal convexity. We supposed that this specimen belongs to $U$. deningeri (se also section about Chlum).

One specimen of P4 (MF/1346/14, ISEA; Fig. 12M) from Kozi Grzbiet was placed among U. arctos. Its size (maximal length $16.5 \mathrm{~mm}$ ) is within the variability for both species, its morphology shares no characters typical either for $U$. arctos or for $U$. deningeri. Specimens of similar morphology are present in both samples. Also specimen from Kövesvárad, sp. B (see below) has similar morphology, but smaller size. This specimen can belong to both species.

Two specimens of M2 from cave C718 (NMP) have rather arctoid position if analyzed the available characters. They are the smallest in the sample. The smaller one (Ra 117; Fig. 12G; maximal length $34.9 \mathrm{~mm}$ ) has neither metastyl nor posthypocon, the crown is relatively open and has well developed constriction between $\mathrm{Pa}$ and $\mathrm{Me}$. In the larger one (Rv 20027; Fig. 12H; maximal length $36.6 \mathrm{~mm}$ ) well developed metastyl is present, the crown is relatively closed, constriction between $\mathrm{Pa}$ and $\mathrm{Me}$ is probably present. The taxonomical determination of these two specimens is problematic and the exact species determination is not possible. We therefore assign them to Ursus sp. But we prefer to interpret them rather as the extreme morphotypes of $U$. deningeri than representatives of $U$. arctos (especially in the case of Ra 117). In the sample from cave C718 
and Koněprusy Caves, there is also a few relatively small or slender canines of uncertain taxonomical status ( $c f$. Wagner 2004).

(8) From the above mentioned, it is obvious, that there is a large overlap between the species that do not allow a species determination of each isolated tooth. The most critical point in this discussion is the absence of knowledge about early representatives of arctoid lineage. The other problem is unknown interpopulation variability of Late Biharian $U$. deningeri. The dominant part of $U$. deningeri sample is composed by the specimens from C 718 and Koněprusy cave - two localities from the same place and of the same or near age. It is therefore possible that some characteristics may indicate rather local particularity than the general species character. But we assume that this is not common case because most of the characters identified as discriminative (between species) we can identified also in later population of $U$. deningeri (Jagsthausen, Mosbach 2, Hundsheim etc.).

The Late Biharian $U$. deningeri is a typical representative of spelaeoid lineage. Although the characters are usually less developed than in the later form, we can recognize all main spelaeoid characters known for Late Pleistocene $U$. spelaeus (with an exception of few ones in M1). We consider the morphology as early spelaeoid but not intermediate between $U$. spelaeus and U. arctos. All three localities represent the bear cave. It supports the idea that the evolution of this lineage was connected with caves since its beginning. We suppose that the behavior of early $U$. deningeri was almost identical as in $U$. spelaeus and that there is no reason to assume it as intermediate between $U$. spelaeus and $U$. arctos. The more often record of Middle Pleistocene $U$. deningeri in non-cave deposits (in respect to Late Pleistocene $U$. spelaeus), we do not interpret as a result of a different life style of these species but only as a result of different frequence of preserved taphocenoses.

\section{Notes to the taxonomic status of bears from other Late Biharian sites}

\section{Kövesvárad}

We fully confirm the Jánossy (1963) determination as U. deningeri for Kövesvárad, sp. A sample. It represents the typical Late Biharian $U$. deningeri in both, morphological and metrical respect. All teeth were placed within $U$. deningeri (sometimes in morphospace of $U$. deningeri / $U$. arctos overlap) in both, cluster and PCA analysis. Concerning the general width-length characteristic of cheek teeth, all specimens of Kövesvárad, sp. A fall inside the variability range for $U$. deningeri and mostly outside the overlap with recent $U$. arctos. Only $\mathrm{m} 2(\mathrm{n}=2)$ are relati- vely broader than usually in Late Biharian $U$. deningeri (Fig. 4C), but the same as in Early Toringian one. Similar characteristic shows also the specimen $(\mathrm{n}=1)$ from Late Biharian locality Lažánky (Czech Republic). The sample of available teeth is too scanty to allow us provide an interpopulation comparison with Czech and Polish localities. We did not find any similarities with $U$. savini mentioned by Jánossy (1963). The small m3 dex. (V.63/203f; Fig. 6L; assigned here to $\mathrm{sp}$. B) has an atypical combination of morphological and metrical characters and occupies an isolated position if compared with $U$. arctos and $U$. deningeri (Fig. 2E). Its morphology differs clearly from simply oval form present in $U$. thibetanus. Based on the comparison and known great variability of this tooth in $U$. deningeri (e.g. Bishop 1982) we assume that this tooth represents an atypically/pathologically developed specimen of this species.

Contrary to sp. A sample, the exact taxonomical status of P4 dex. (V.63/252, Fig. 7L; assigned here to sp. B), determined by Jánossy (1963) as U. mediterraneus (the later synonym of $U$. thibetanus), is ambiguous. (a) It differs from $U$. deningeri especially by its small size (maximal length $14.7 \mathrm{~mm}$; see also Jánossy 1963). The smallest specimen in our sample of $U$. deningeri is $\mathrm{P} 4$ dex. from Koněprusy Caves (Rv 20029, NMP) with maximal length $15.9 \mathrm{~mm}$. But this specimen is deningeroid in its shape (well developed buccal constriction). Maximal length of discussed Kövesvárad P4 is also under the lower limit for other studied (Jagsthausen, Mosbach 2, Hundsheim, Bacton) and published (e.g. Prat \& Thibault 1976, Argant 1980, García 2003, Baryshnikov 2006) early Middle Pleistocene $U$. deningeri samples. It bears no morphological characters typical for $U$. deningeri, but it resembles some specimens in its general morphology, particularly P4 dex. (MF/1346/28; Fig. 7I; maximal length $19.0 \mathrm{~mm}$ ) and P4 sin. (MF/1346/14; Fig. 12M; maximal length $16.5 \mathrm{~mm}$ ) from Kozi Grzbiet (both in ISEA). The arctoid affinity of the latter is discussed above. (b) It falls into the lower half of the size range of $U$. arctos and occupies rather peripheral position in its length-width ratio (Fig. 8A). Although the protocon is usually relatively larger and more anteriorly placed in $U$. arctos than in specimen from Kövesvárad, the appropriate arrangement occurs in $U$. arctos throughout all subsamples (e.g. Kamchatka specimen, inv. No. 40678, NHMW). (c) It is somewhat larger than the recent sample of $U$. thibetanus, but near the mean value of $U$. $t$. mediterraneus (Baryshnikov 2010). It also fits well to $U$. thibetanus in length-width ratio (if we included the specimens of $U$. t. mediterraneus in the scatter plot (data from Baryshnikov 2010), the Kövesvárad P4 would be placed in their center). Unlike it, the PCA (Fig. 9A) places this tooth rather among $U$. arctos than $U$. thibetanus. Concerning its morphology, it differs from $U$. thibetanus in more posterior position of protocon and steeper descending mesial arm of paracon ( $c f$. Fig. 7M). According to our comparison, the 
top of paracon is placed more posteriorly (with respect to the anterior edge of tooth) in $U$. thibetanus than in $U$. arctos or $U$. deningeri and, subsequently, paracon's mesial arm descends more gradually in $U$. thibetanus than in other two species. But due to the limited size of our comparative sample of $U$. thibetanus, this result will need the further confirmation. As apparent from above, the P4 dex. (V.63/252) does not express unambiguous affinity to any bear species. According to our opinion, this tooth belongs most probably to arctoid bear, although its affinity to U. t. mediterraneus cannot be wholly rejected for the moment. We propose the preliminary determination of this tooth as Ursus sp. (cf. arctos).

The presence of U.t. mediterraneus is proven in Europe since the beginning of Toringian (e.g. Heller 1949, Thenius 1958, Argant 1991, Crégut-Bonnoure 1996, Baryshnikov 2010). As demonstrate by Wagner et al. (2012) there is no unambiguous evidence of the species during whole Biharian. On the other hand, some other oriental elements (Petauria, Macroneomys) occur in Europe during the last Biharian interglacial (OIS 17) and therefore the presence of $U$. thibetanus is also conceivable for this period. Except for the specimen from Kövesvárad, another small tooth was described from the latest Biharian locality Přezletice (Czech Republic; Fejfar 1993). Fragment of an extremely damaged $\mathrm{m} 1 \mathrm{dex}$. from this locality was determined as Ursus cf. mediterraneus by Fejfar (1993, Fig. 8/3). Although the fragment is too damaged to allow any taxonomical result, it seems that its size was considerably under the limit of $U$. deningeri.

\section{Chlum}

All the material assigned here to sp. A, originating from two localities - Chlum 1 and 4, was determined as $U$. deningeri by Wagner (2004). We can confirm it with several specifications. The taxonomical determination is ambiguous in M2 sin. (R 2042; NMP) (see paragraph about sp. B for details) and in $\mathrm{m} 3 \mathrm{sin}$. (Ra 2416; NMP).

The latter tooth (originated from Chlum 1 locality; Fig. 12J) is relatively small (maximal length $20.2 \mathrm{~mm}$ ) with oval triangular outline. The size is on the lower limit of $U$. deningeri, but still inside the species variability range. It bears no morphological characters typical for spelaeoid lineage but its outline is also not typically arctoid. It is placed among $U$. arctos by PCA (Fig. 2E), but its lengthwidth proportions are deningeroid. We assume that this specimen represents an extreme morphotype of $U$. deningeri rather than $U$. arctos. But the unambiguous determination is not possible and we determine it as Ursus cf. deningeri. Another problematic third lower molar originates from locality Voigtstedt (all material is deposited in SFQW). We revised three $\mathrm{m} 3$ from this locality. Two of them belong to typical $U$. deningeri (1966/7746,
1966/5091). But the third one represents the small (although inside the published variability of $U$. deningeri, see e.g. Bishop 1982 or Baryshnikov 2006) and deeply worn m3 sin. (1966/7751 = Voi. 3197; maximal length 19.9 mm; Fig. 12L) with oval outline. If it is placed into maximal length-trigonid width scatterplot, it will be placed among $U$. arctos, out of variability range of $U$. deningeri. Thenius (1965) is aware of this problem and determines this tooth conditionally as Ursus cf. deningeri. We determine it as Ursus sp. It is possible that this tooth belongs to an arctoid bear. As mentioned already by Thenius (1965, see also Baryshnikov 2010) its size is above the variability for $U$. $t$. mediterraneus with an exception of unusually large specimen from Azych cave (type of U. karabach Vereschagin \& Tichonov, 1994).

Two specimens (both from Chlum 4) were assignated to sp. B. One of them (m1 sin., Ra 2147, NMP) was determined as $U$. t. mediterraneus by Wagner (2004) but later re-determined as Ursus sp. by Wagner et al. (2012). This $\mathrm{m} 1$ (Fig. $3 \mathrm{~K}$ ) is clearly distinguishable from $U$. thibetanus by (a) presence of relatively mesial placed End1, (b) presence of a small End 2 that is in contact with distal swelling of Med-c and (c) absence of enamel crest connecting Med and Hyd. It differs from $U$. deningeri especially by its small dimensions. It has the Med-c of type II. It differs somewhat in general shape and trigonid width/talonid width ration from $U$. arctos. The other tooth is $\mathrm{m} 2$ dex. (Ra 2148, NMP; Fig. 5K). It is relatively small, with its maximal length $(23.8 \mathrm{~mm})$ under the lower limit of Late Biharian U. deningeri as well as for other comparative collections (Jagsthausen, $\mathrm{n}=24$; Mosbach 2, $\mathrm{n}=39$; Mauer, $\mathrm{n}=9$; Hundsheim, $\mathrm{n}=8$ ). Bishop (1982) lists minimal value $23.7 \mathrm{~mm}$ for bears from Westbury and also two specimens from Bacton are of the same size or smaller than the Chlum, sp. B specimen (but see below for problematic of Bacton bears). On the other hand, the minimum value for bears from Vallonet is above this specimen (Moulle 1992). It is larger than U. t. mediterraneus with an exception of Azych specimen. Both of the above mentioned teeth were placed among $U$. arctos in the analysis (Fig. PCA 2C, D; see Results). It is worthy to note that if we increase artificially all the measurements of $\mathrm{m} 2$ dex. (Ra 2148) about $10 \%$ it will be still placed among the brown bear by PCA. That means that this tooth is distinguished from U. deningeri sample rather by its general arrangement than the maximal size. Both of these teeth share a unique combination of characters that is typical neither for $U$. arctos nor $U$. deningeri. But we presume that their affinity to $U$. arctos prevails considerably over that to $U$. deningeri and we assign them, tentatively, to the exclusive arctoid lineage and refer them as Ursus cf. arctos. The differences to recent brown bear can be caused, among others, by (a) lost of variability in the recent brown bears, (b) changes in selection pressures or (c) the presence of independent lineage of arctoid 
bears in the late Early and early Middle Pleistocene of Europe without ancestral relationship to recent form. It seems possible that both specimens belong to one individual. It is questionable if also M2 sin. (R 2042, NMP; Fig. 12I) could belong to this form. This specimen belongs among the smallest ones in studied material of $U$. deningeri and was placed somewhat distantly from the other $U$. deningeri (but also from $U$. arctos) by the PCA (the right lower quadrant). Its morphology is relatively simple (but tooth is worn). Similar in size and morphology (if possible to assess) is also M2 dex. (R2047, NMP). Unfortunately, this specimen is heavily damaged (enamel preserved only in part of trigon). We determine both of them as Ursus sp. They can belong to $U$. deningeri as well as to the arctoid form from Chlum 4.

Except cheek teeth, the mandibular fragment with alveoli of three anterior premolars and a canine ( $\mathrm{Ra} 2121$, NMP) represents the bear species clearly distinguishable from $U$. deningeri (as mentioned above, no anterior premolars are present in mandibles of studied Late Biharian $U$. deningeri). This specimen was described by Wagner (2004, Fig. 1) and determined as U. t. mediterraneus (and Ursus sp. by Wagner et al. 2012). Subsequently Baryshnikov (2010, table 3 ) assigns the canine from this mandible and two other small lower canines from this locality (all material originates from Chlum 4) to the same subspecies. We assign the mandibular fragment (Ra2121) to Ursus cf. arctos, the same taxon as both above discussed small lower molars. The taxonomical status of two other small canines is unclear. They can belong to the same taxon, but similarly small/slender specimens occur also in C 718 and Koněprusy Caves. We determine them provisionally as Ursus sp.

\section{Gombasek}

Kretzoi (1938) describes U. etruscus gombaszogensis from this locality and integrates it as a member of spelaeoid lineage: etruscus-gombaszogensis-savini-deningeri. The affiliation with spelaeoid lineage is generally accepted (see also the result of Pa-height/maximal length ration for one M1 in Kurtén 1955a). Some authors regard this taxon as representative of an advanced U. etruscus (Erdbrink 1953, Kurtén 1955a, Thenius 1965), other consider its conspecifity with U. savini (Baryshnikov \& Foronova 2001) or U. deningeri (e.g. Kurtén 1958, Torres 1992). Baryshnikov (2007) synonymizes this form with $U$. $d$. suessenbornensi. Jánossy (1963) states that bears from Gombasek are somewhat less evolved, at least in several specimens, than typical $U$. deningeri (incl. Kövesvárad specimens). He warns that the material originates from several karst fissures of different age and notes that in material collected after Kretzoi's paper there is present also the typical U. deningeri. Unfortunately it is not clearly evident if the presence of differently old samples is supposed already for the type collection or only for the material collected later or if it means that later collected material is of different age than the type collection.

The studied material from Gombasek differs clearly from $U$. etruscus (by its larger size and more complicated occlusal surface) as well as from $U$. savini (the latter has more diversified occlusal surface of cheek teeth, especially in $\mathrm{p} 4$, as mentioned already by Kretzoi 1938). All studied teeth correspond to those of $U$. deningeri. They are placed by PCA relatively often near the $U$. deningeri-U. arctos boundary. $\mathrm{m} 1$ is deningeroid in its general form (Me-c type I, morphology of entoconid), but its entoconid complex is relatively simply built. In both available specimens (only two specimens are unworn) there are present a large End1 and a small mesial cusp, that we interpreted as mesostylid. The two other teeth, strongly worn, show similar arrangement, if possible to deduce from preserved remains. The same morphology is present also in a few specimens of studied sample of $U$. deninergi, but it represents only an infrequent morphotype (that we regard as plesiomorphic). In three preserved $\mathrm{m} 1$ from locality Chlum 1 the morphology of End-c seems to be very similar to those from Gombasek. But these teeth are too damaged/worn to allow an exact evaluation. One P4 (V.789, HNHM; not a part of the type series) is relatively small (maximal length 16.7) bearing a small metastyle. But we assume that it belongs to the same taxon as other teeth. All in all, the bears from Gombasek represent an unambiguous $U$. deningeri, perhaps somewhat older then OIS 17. Kretzoi (1941) assigns two small bear canines from this locality to $U$. stehlini $(=U$. thibetanus) but they were not found during the revision of material. Their taxonomical status is unknown.

\section{Süßenborn}

Among the first, Freudenberg (1914) concerns himself with the taxonomical status of the bear from Süßenborn and assigns it to $U$. deningeri. Soergel (1926) describes in detail all in that time available bear material from this locality and bases on it a new species, U. suessenbornensis. He supposes that this bear represent an early member of spelaeoid lineage. This opinion was subsequently broadly accepted (e.g. Thenius 1965, Kurtén 1969, Torres 1992, Argant \& Crégut-Bonnour 1996, García 2003, Baryshnikov 2007). The other specialists suppose its affinity with arctoid lineage (Erdbrink 1953, Mazza \& Rustioni 1994, Rabeder et al. 2010). Kurtén (1969) defines two groups of $U$. deningeri and considers that they represent two evolutionary stages of $U$. deningeri. He revised all the available material from Süßenborn and resulted that (a) concerning dental characters it represents intermediate form between his two groups, (b) its metapodial bones are large but in its proportions more arctos- than deningeri-like, (c) concerning its taxonomical status, it represents a specialized 
steppe-form belonging to $U$. deningeri (see also Kurtén 1976). Baryshnikov (2007), who also revised the material personally, assigns the material to $U$. deningeri. He uses the name $U . d$. suessenbornensis for bears (mostly) from Late Biharian localities (but also Jagsthausen and Petralona) and distinguishes it from the nominal subspecies especially by (a) narrower $\mathrm{P} 4$ and (b) less diversified End-c in $\mathrm{m} 1$. Contrary to them, Rabeder et al. (2010) assign this bear to arctoid lineage. According to their analyses (a) the most of teeth (except one large M2) are inside the variability for both $U$. deningeri and $U$. arctos (especially the Middle Pleistocene one), (b) the proportion of metapodial bones are arctoid (see also Koby 1953) and different from the state in spelaeoid lineage, (c) somewhat larger size of metapodial bones can be explained by sexual dimorphism or by differences in stratigraphical age and (d) concerning its taxonomical status, the Süßenborn bear represents a large form of arctoid bear. Rabeder et al. (2010) use subsequently the name $U$. (arctos) suessenbornensis for all the bears from late Early to early Middle Pleistocene assigned by them to arctoid lineage.

We included into our analysis all the available cheek teeth material from Süßenborn $(n=9)$. According to our analysis not only M2 sin. (1965/2424) but also most of other teeth represent typical Late Biharian $U$. deningeri. The exceptions are $\mathrm{m} 1$ sin. (1965/2426) and $\mathrm{m} 2 \mathrm{sin}$. (1965/2422; Fig. 12F). The latter tooth is relatively broad (Fig. 4C) and bears almost no central constriction. It was placed rather among $U$. arctos than $U$. deningeri by PCA, but its position is relatively isolated. This tooth is preserved in the incomplete mandible that bears no anterior premolars. We prefer to interpret this tooth as extreme morphotype inside the variability range of $U$. deningeri and we therefore assign it to this species. Kurtén (1969) supposes that this mandible belongs to a female individual of $U$. deningeri. In the Süßenborn collection there is six mandibles and their fragments (partly no complete diastemata are preserved). Mandible dex. (1964/1306) bears probably an alveolus of p1 and mandible dex. (1965/2421) could bear a rest of alveolus of p3 (but the area is damaged). There are present $\mathrm{m} 2$ in both of these mandibular fragments, which morphometric characteristic fit well with that of $U$. deningeri. But it is necessary to note that according to Rabeder et al. (2010) the absence of anterior premolars occurs also in the early arctoid bears.

The only $\mathrm{m} 1$ (Fig. 3N) bears interesting combination of characters. Its general form is more similar to U. deningeri, the crown is open (especially apparent in Pad). Its metaconid belongs rather to type II, but it does not reach the contact with Pad and the lateral bulging is present in trigonid. The size is within the variability for both species. The maximal length/trigonid width ratio is rather arctoid (Fig. 4A), but if we would include specimens from Jagsthausen or Mosbach 2 into this scatter plot, more teeth of $U$. deningeri would have similar position (Early Toringian $U$. deningeri is sligthly relative broader than the Late Biharian one). This tooth is placed among $U$. arctos by PCA but within $U$. deningeri by one-way ANOVA. The morphology of End-c is especially interesting. There is present only End1 with a low and slightly segmented mesial arm. We have not found similar morphology in any extant brown bear. There are a few specimens of $U$. deningeri bearing only End1 but also morphology of their End-c differs from that in Süßenborn specimen. The most similar morphology of End-c has m1 dex. (18/31, Institute of Paleontology, University of Vienna) from DeutschAltenburg 4B. This specimen is also similar in size and proportion with that from Süßenborn. It differs from the latter by noticeably more closed crown (e.g. the Süßenborn specimen is more evolved in spelaeoid direction). For the moment we are not able to determinate this tooth on the species level, but its affinity to $U$. deningeri is not possible to exclude. Rabeder et al. (2010) base their determination especially on the proportion of metapodial bones. It is therefore possible that both species are present in this assemblage but we do not find any unambiguous evidence for the presence of arctoid bear based on the mandibular and dental material.

M1 dex. (1965/2425; Fig. 10N) was designated by Baryshnikov (2007) as lectotype. Its taxonomical determination is therefore especially important. Rabeder et al. (2010) indicate that length and width parameters of this tooth are within the variability of Middle Pleistocene brown bears. This tooth is relatively large. Its maximal length is outside the variability of recent brown bears and only three specimens exceed it in maximal length if the data from middle and late Middle Pleistocene brown bears are included. But it is only slightly above the mean value for Late Biharian U. deningeri. It is wholly deningeroid in its length/width proportion (see Fig. 8C for maximal length/width of central constriction). If we compare the maximal length and posterior width in scatter plot, the result will be similar. Adding the data of Middle Pleistocene arctoid bears from Kurtén $(1959,1975)$ will increase importantly the overlap between both species, but despite it the Süßenborn specimen will stay outside the variability of $U$. arctos. The maximal length/anterior width ratio is not discriminative for $U$. arctos and Late Biharian $U$. deningeri. The spelaeoid affinity of this specimen is confirmed also by Kurtén (1955a) for Pa-height/maximal length ration. We therefore see no evidence that this tooth could belong to other species than $U$. deningeri. We regard as unambiguous that name $U$. suessenbornensis is later subjective synonym of $U$. deningeri.

The exact stratigraphical age of the bear material is ambiguous. Rabeder et al. (2010, p. 112) place this bear with a question mark near the bears from Deutsch-Altenburg 4B, i.e. before the Jaramillo event. Although a presence of old 
strata is documented by fossil evidence in this locality, we have doubt that available bear teeth could belong to this old stratigraphical level. Their morphology (e.g. more open crowns) is similar to the Late Biharian U. deningeri and differs from earlier forms.

\section{Bacton}

We studied the dental material of bears from Cromer Forest-bed Formation (CF-bF) deposited in the NHM (incl. the type specimen of $U$. savini). Due to their taxonomic ambiguity we do not include them into our analysis before the rest of material, deposited in Norwich Castle Museum, will be revised. Nevertheless, we want to make few preliminary notes concerning their taxonomical status.

Scarcity of material, ambiguous stratigraphical position and unusual combination of characters in bear material from $\mathrm{CF}-\mathrm{bF}$ are the main reasons for long-term controversy about their taxonomical status. In the most of the CF-bF localities, there are documented two main stratigraphical levels, traditionally called Pastonian (Early Pleistocene) and Cromerian (early Middle Pleistocene) (e.g. West 1980, Lister 1996, Preece \& Parfitt 2000). All specimens studied in NHM show more advanced characters than would be expected in the Early Pleistocene forms (e.g. U. etruscus or Ursus sp. from Deutsch-Altenburg 4B). We therefore suppose that all the bear material belongs to the early Middle Pleistocene level (approximately OIS 19-13). More precise stratigraphic determination is mostly impossible. Two localities are of special interest (a) West Runton for which a more precise stratigraphic position is available and (b) Bacton, the type locality of $U$. savini Andrews, 1922.

West Runton Freshwater Bed (WRFB) is placed, based on the arvicolids ( $c f$. Hinton 1926), into the last Biharian interglacial by Fejfar \& Heinrich (1983), West (1980) supposes longer period (at least two last Biharian interglacials). Maul \& Parfitt (2010) analyze the newly excavated micromammals material from West Runton Elephant Site and indicate that micromammals from WRFB form uniform assemblage dated into the early OIS 17 . It is therefore possible to assume that the available bear material (lately revised by Lewis et al. 2010) originates most probably from the Last Biharian interglacial, analogous to the analyzed Middle European samples. P4 dex. (M17962) is small, relatively broad, its protocon is large and relatively mesialwards placed, the buccal wall is almost straight. P4 sin. from Overstrand (M17940) is similar in general form to the West Runton specimen. But it differs from it by (a) larger size, (b) presence of weak buccal constriction and (c) being relatively narrower. P4 from West Runton is more similar to $U$. arctos than $U$. deningeri in its size, proportion as well as morphology. Both available first upper molars, M1 sin. (M6083) and M1 sin. (M17941), are above the size limit for recent sample of $U$. arctos (but inside the variability of Middle Pleistocene brown bears). Both of them were placed among U. deningeri by PCA (M17941 near the boundary with $U$. arctos). In the scatter plot of maximal length/posterior width, M1 sin. (M17941) is placed in the overlap between Middle Pleistocene $U$. arctos and $U$. deningeri, the latter (M6083) outside the variability of $U$. arctos. The latter tooth has markedly narrower anterior lobe than the posterior one and relatively large parastyle. Parystyle is smaller than metastyle in M1 sin. (M17941). M2 dex. (M6080) is large with well developed metastyle and probably also posthypocon (tooth is worn in this part) but with relatively short talon. Lewis et al. (2010) describe and figure additional $\mathrm{m} 1 \mathrm{dex}$. This tooth is almost identical in its morphology, size and proportion with $\mathrm{m} 1$ from the Late Biharian $U$. deningeri from our sample. If it is placed in the scatter plot for maximal length/talonid width (data from Lewis et al. 2010) it will be outside the variability for $U$. arctos (incl. Middle Pleistocene ones). We can summarize that in West Runton an unambigous $U$. deningeri is determinable but most probably also arctoid bear can be present. This opinion is in accordance with results by Rabeder et al. (2010) based mostly on the metapodial bones.

Andrews (1922) assigns all the bears from CF-bF to a new spelaeoid species $U$. savini and designates the right mandible (16448, NHM) from Bacton as the holotype. Three main models describing phylogenetical position of $U$. savini are currently in use: (a) $U$. savini is an ancestor of $U$. deningeri (or its earliest subspecies) and, as such, represents early spelaeoid form (e.g. Kurtén 1969, 1976, García \& Arsuaga 2001, García 2003), (b) U. savini is synonymous with $U$. deningeri, possible one of its subspecies (e.g. Torres 1992, Mazza \& Rustioni 1994, Argant \& CrégutBonnour 1996, Grandal \& López-González 2004, Rabeder et al. 2010) and (c) U. savini is a representative of an independent lineage of small spelaeoid bears (continuing till the Late Pleistocene), representing the sister clade to the main $U$. deningeri-U. spelaeus lineage (e.g. Baryshnikov 2006, 2007; Sher et al. 2011). All CF-bF bears are usually included in $U$. savini. Nevertheless, we prefer to restrict this taxon only to the bears from Bacton ( $c f$. Kurtén 1969). The material from Bacton (type locality) form a dominant part of CF-bF bear material. Its exact relationship (both taxonomical and stratigraphical) to bears from other localities is ambiguous. It is possible that also the rest of CF-bF material belongs to the same taxon but we assume that this is necessary just to confirm rather than accept a priori. West (1980) argues, based on the pollen analysis, for the age Cromerian III and IV (i.e. OIS 15 and OIS 13) for this locality. García (2003) assumes age OIS 17. There is no evidence supporting Kurtén's (1969) opinion that this bear could be of pre-Cromerian age. We accept the West's determination and consider the Bacton bears as Early Toringian (i.e. similar age like Mauer or Mosbach 2). 
The most of the material (in NHM) is represented by mandibles with cheek teeth. The mandibles are relatively small, bearing no anterior premolars. The only available skull (housed in Norwich Catel Museum) has well developed glabella and bears P3 (Fig. in McWilliams 1967, photo in Stuart 1982, see also Kurtén 1969). It does not differ in size from other skulls of $U$. deningeri (Kurtén 1959). Also the maxillary fragment in NHM (M17918) bears probably an alveolus of P3. Most of the upper teeth deposited in NHM originated from one unpreserved skull (M17963). Both P4 and M1 are deningeroid in their size, proportions as well as morphology and do not differ significantly from the Late Biharian $U$. deningeri. Both associated $\mathrm{M} 2$ are very small (on the lower limit for U. deningeri) and rather arctoid in proportion. Damaged M2 from maxillary fragment (M17918) are similar in size with U. deningeri. P4 sin. (M17939) is simply built with more mesial position of $\mathrm{Pr}$ than in two above mentioned specimens. It is rather larger, in scatter plot of maximal length/maximal width it would be in the area of overlap for $U$. arctos and $U$. deningeri. In general, the upper teeth differ neither in size nor in morphology from those of Late Biharian $U$. deningeri. Results are the same for the upper teeth from other CF-bF localities $(n=6)$. The $\mathrm{p} 4$ are approximately of the same size and proportion as the Late Biharian $U$. deningeri $(\mathrm{n}=10$, mean $14.6 \mathrm{~mm}$ and minimum $12.6 \mathrm{~mm}$ for maximal length). Their morphology is spelaeoid (with large paraconid in most of them) and in average more advanced than in the Late Biharian U. deningeri. $\mathrm{m} 1$ are in average smaller compared to $U$. deningeri, although inside the species variability (our data and Bishop 1982). From the whole sample $(n=11)$, only two specimens have maximal length about the average value of $U$. deningeri. In the maximal length/talonid width scatter plot, the small teeth (maximal length $<26.0 \mathrm{~mm}$ ) are arctoid, outside the variability for Late Biharian $U$. deningeri. Two larger teeth are more deningeroid, M6186(1246) (maximal length $27.5 \mathrm{~mm}$ ) even outside the variability of $U$. arctos (incl. Middle Pleistocene ones) with its position near the specimen from West Runton (data from Lewis et al. 2010). If we use maximal length/trigonid width scatter plot, the general pattern will stay the same but less apparent. Three teeth can be included into the PCA (Fig. 2C). All of them are placed among $U$. deningeri, two small ones (incl. type specimen) near the boundary of U. arctos. Two $\mathrm{m} 1$ originate from other CF-bF localities (Mundesley, Sidestrand). Both are large (maximal length above the maximum for Bacton), with their proportions very similar to that from Bacton. Similar results are provided by $\mathrm{m} 2$. $\mathrm{m} 2$ is in average smaller (minimum value for maximal length for Bacton is under the minimum for Late Biharian $U$. deningeri as well as bears from Westbury) and relatively broader than Late Biharian $U$. deningeri. In maximal length/trigonid width scatter plot, all the teeth from Bacton
( $\mathrm{n}=10)$ are inside the variability of $U$. arctos, mostly outside or on the limit for the Late Biharian $U$. deningeri. Seven teeth can be analyzed by PCA. Five of them are placed among $U$. arctos, the two largest on the boundary between $U$. arctos and $U$. deningeri (Fig. 2D). Four $\mathrm{m} 2$ come from other CF-bF localities. Those from Overstrand, Mundesley and Sidestrand are within the size variability of Bacton sample that from East Runton exceeds it. Concerning maximal length/trigonid width ratio, all four teeth are very similar to those from Bacton. Differences in size of $\mathrm{m} 3$ are smaller than in $\mathrm{m} 1$ and $\mathrm{m} 2$. Their proportions are mostly intermediate or deningeroid. One specimen (M17916) is unusually small, but it represents only the extreme variability of this tooth. Morphology of all three lower molars is in general deningeroid.

We can conclude that Bacton bears (a) do not differ from the Late Biharian $U$. deningeri in upper teeth (but very low $n$ ), with possible exception of M2, (b) do not differ significantly from the Late Biharian $U$. deningeri in size and proportion of $\mathrm{p} 4$ and $\mathrm{m} 3$, (c) have in average more evolved $\mathrm{p} 4$ than the Late Biharian $U$. deningeri and (d) differ from the Late Biharian $U$. deningeri in having in average smaller and relatively broader $\mathrm{m} 1$ and $\mathrm{m} 2$. Only one lower $\mathrm{m} 1$ is available from West Runton, it does not differ from the Late Biharian $U$. deningeri but it is also very similar in its size and proportions to the larges specimen from Bacton. The lower teeth from other CF-bF localities show the same pattern as the Bacton bears but are in average larger. This characteristic would support the Early Toringian age for these bears. Based on the proportion comparison of M1 $(n=34), m 1(n=24)$ and $m 2(n=46)$ from Mosbach 2 (Naturhistorisches Museum Mainz) and Hundsheim (Institute of Palaeontology, University of Vienna) with those from the Late Biharian, we can conclude that (a) M1 are the same for the both Late Biharian and Early Toringian forms, (b) in relative width of trigonid in $\mathrm{m} 1$, both groups are very similar but the Early Toringian sample is slightly more broader, (c) in relative width of talonid in $\mathrm{m} 1$, this trend gets stronger and the Mosbach 2 specimens are intermediate between Late Biharian $U$. deningeri and $U$. arctos (incl. Middle Pleistocene), specimens from Hundsheim are more similar to the Late Biharian $U$. deningeri and (d) in relative width of trigonid in $\mathrm{m} 2$, the sample from Mosbach 2 is more relatively broader than the Late Biharian one (Hundsheim takes intermediate position) and is almost indistinguishable from $U$. arctos (in PCA specimens from Mosbach would be placed widely among $U$. arctos and include the variability of Bacton teeth). Above described characteristic of Early Toringian $U$. deningeri is in accordance with data published by García (2003) for Sima de los Huesos and other localities. The CF-bF localities other than Bacton do not differ from the Early Toringian population of $U$. deningeri from Central Europe and we find no evidence for their separation. 
The Bacton specimens are in average smaller and have somewhat broader $\mathrm{m} 1$ than Toringian sample of $U$. deningeri, moreover the mandibles are unusually small. But this characteristic is valid only if we accept that (a) the rest of CF-bF specimens does not belong to the same taxon and (b) the available Bacton sample is representative for the taxon.

We reject the model, that $U$. savini (as written above, we restricted this taxon only for bears from Bacton) is an ancestral form in respect to $U$. deningeri. More evolved $\mathrm{p} 4$, relatively broad $\mathrm{m} 1$ and especially $\mathrm{m} 2$ and considerably diversified occlusal surface in connection with probably Toringian age do not allow to accept this form as ancestral to the Late Biharian U. deningeri (the same would be valid even if we accept the Late Biharian age for Bacton bears). Inclination of Pad in $\mathrm{m} 1$, diversification of End-c in $\mathrm{m} 2$ or outline in $\mathrm{m} 3$ ( $c f$. García \& Arsuaga 2001) are not less evolved in bears from Bacton than in the Late Biharian U. deningeri. According to us, also its small size is not plesiomorphic character ( $c f$. Musil 2001 for data from Untermaßfeld). The morphometric characteristic of bears from Bacton could be explained as a result of diminution under the island conditions (this interpretation we prefer in present; some effects of geographical isolation are presumed also by García 2003). But this explanation would require an assumption, that bears from other $\mathrm{CF}-\mathrm{bF}$ localities and especially from Westbury are not contemporary with those from Bacton. Alternatively, bears from Bacton can be interpreted as normal $U$. deningeri from the lower part of the size range (but the small size of mandibles would need more precise explanation). We are not able to corroborate/falsify the Baryshnikov's model (2006, 2007) expecting the independent lineage of small cave bears. But we think that, at least some, similarities detected by Baryshnikov could be explained by parallelism caused by independent process of diminution within the cave bear lineage.

\section{Eberbach}

Rüger (1928) and Rode (1935) include bears from this locality in U. deningeri. Rüger (1928) assumes that these bears are more primitive than those from Mosbach and Mauer. This opinion is accepted also by Heller (1939) and Thenius (1965). According to the former, this bear represents a separate species $U$. eberbachensis, an intermediate form between $U$. etruscus and $U$. suessenbornensis. Kretzoi (1941) assumes its conspecifity with bear from Gombasek. Contrary to it, Erdbrink (1953) synonymizes this taxon with $U$. arctos. According to Baryshnikov (2007) this bear belongs to the lineage of small spelaeoid bears and is conspecific with $U$. savini.

M1 dex. (M.3744; Fig. 10O) is relatively large, above the maximum of recent $U$. arctos. It is inside the variability of Middle Pleistocene $U$. arctos, but also in this sample only two teeth are larger than that from Eberbach. Its proportion is deningeroid. It is outside the $U$. arctos variability in width of constriction/maximal length scatter plot (Fig. 8C) as well as in scatter plot for posterior width/maximal length (but in this case near the variability for the Middle Pleistocene $U$. arctos). It exceeds specimens from Bacton $(n=2, N=1)$ in maximal length, one specimen from Overstrand is larger. Its morphology is rather deningeroid: (a) well apparent lingual constriction, (b) mestayl larger than parastyle and (c) relatively open crown, especially metastyle and parastyle (but due to the abrasion it is not unambiguous). This tooth was determined as spelaeoid also by all multivariate analyses.

m1 dex. (M.3743; Fig. 30) is rather small, in the lower part of the variability for the both Late Biharian and Early Toringian $U$. deningeri. It is at the boundary between $U$. arctos and $U$. deningeri in its proportions. In scatter plot for trigonid width/maximal length (Fig. 4A), it is outside the variability for the Late Biharian $U$. deningeri. It is inside the variability for bears from Bacton and Early Toringian $U$. deningeri (in the latter on its limit), if these would be added. In talonid width/maximum length scatter plot, this is on the limit for U. arctos, the Late Biharian and Early Toringian $U$. deningeri and outside the variability for bears from Bacton. Its End-c proportion are arctoid (Fig. 4B), with small End 2 bearing short mesial arm. It differs significantly in its End-c morphology from both, bears from Gombasek and Bacton. Its general morphology and morphology of Med-c are rather deningeroid. It is identified as arctoid by cluster analysis (Appendix 3, Fig. 1A) and PCA (Fig. 2C; in the latter placed near the specimens of $U$. deningeri with small End 2) and as deningeroid by one-way ANOVA.

$\mathrm{m} 2$ dex. (M.3742; Fig. 5O) is of intermediate size. It is more similar in its proportions (trigonid width/maximum length) to $U$. arctos than to the Late Biharian $U$. deningeri, but still within the variability of the latter (Fig. 4C). In this character it fits well with the Early Toringian U. deningeri and is also within the variability for bears from Bacton. Central constriction is well developed on the buccal side, both EPrd and EMed are present. It is placed among $U$. deningeri (near the boundary with $U$. arctos) by PCA and among $U$. arctos by one way ANOVA. The arctoid affinity in the analysis can be affected by higher relatively width of this tooth. This character seems to be arctoid in the comparison with the Late Biharian $U$. deningeri but is characteristic also for the Early Toringian $U$. deningeri. m3 dex. (M.3745; Fig. 6O) is intermediate in its size and rather arctoid in its proportions (Fig. 4D). This tooth is determined as arctoid by one-way ANOVA.

Based on the results above, we can conclude that (a) M1 is deningeroid in its morphometric characteristics and (b) lower teeth (bi) differ significantly from Gombasek 
specimens, (bii) bear no particular characters typical for bears from Bacton (the characters common for bear from Eberbach and Bacton are present also in Early Toringian $U$. deningeri), (biii) $\mathrm{m} 1$ and $\mathrm{m} 2$ differ in proportion from Late Biharian $U$. deningeri but are in the variability range for Early Toringian one (m1 on its limit) as well as $U$. arctos. We are not able to determine this bear on the species level for the moment. But we consider deningeroid affinity as more probable based on the teeth morphology (but it needs further confirmation by direct comparison with Middle Pleistocene $U$. arctos). If these teeth belong to $U$. deningeri, it is more probable that it will be of the (Early) Toringian than Biharian age.

\section{Sackdilling}

Heller (1956) describes a new bear species, U. sackdillingensis, on the basis of one isolated M2 dex. (Hsa 117; Fig. 110). He assumes that this bear represents a very early representative of spelaeoid lineage (based mostly on the diversification of occlusal surface). Torres (1992) and Hilpert (in Ambros et al. 2005) suppose the possible synonymy with $U$. thibetanus/mediterraneus. Baryshnikov (2007) synonymizes this species with $U$. arctos. Lewis et al. (2010) include this form among brown bear-like populations.

The tooth is relatively small (Figs $8 \mathrm{D}, 9 \mathrm{C}$ ). Its maximal length $(33.7 \mathrm{~mm})$ is under the lower limit for $U$. deningeri, as well as for bears from Bacton $(\mathrm{n}=2, \mathrm{~N}=1)$ or Untermaßfeld (Musil 2001, $\mathrm{n}=2, \mathrm{~N}=1$ ) but inside the variability for the bear from Vallonet (Moullé 1992, $\mathrm{n}=25$, mean $38.35 \mathrm{~mm}$, min. $31.7 \mathrm{~mm}$ ) and Trinchera Dolina 4 (García 2003, $\mathrm{n}=10$, mean $38.43 \mathrm{~mm}$, min. $27.8 \mathrm{~mm}$ ) as well as $U$. arctos. It is above the upper limit for the both fossil and recent $U$. thibetanus (Pei 1934, Erdbrink 1953, Crégut-Bonnoure 1996, Baryshnikov 2007). Its talon is short and relatively broad. No metastyle is present. There are three small cusplets behind the hypocon, but posthypocon is not present. The occlusal surface is well diversified but we find no significant differences from $U$. arctos. We determine conditionally the bear from Sackdilling as Ursus cf. arctos. But due to its stratigraphical age (pre-Brunhes/Matuyama) it is necessary to confirm this determination by further comparison with bears from the period between Jaramillo and Brunhes/Matuyama boundary.

\section{Note to Untermaßfeld}

The taxonomical status of bear population from the end of the Early Pleistocene is a subject of intensive discussions in the last years (see Wagner 2010 and references therein). As we do not have any possibility to revise material from these localities personally and their taxonomical status was not a subject of this study we would like only to make a short note to the bears from Untermaßfeld. Musil (2001) as first considers arctoid affinity of these bears. The opinion is accepted by several subsequent researchers (Olive 2006, Palombo et al. 2008, Rabeder et al. 2010). The others suppose that these bears represent an early spelaeoid form (García 2004, Baryshnikov 2007, Argant 2009). Based on the preliminary evaluation of published data (Musil 2001), we agree with the latter and assign the bear from Untermaßfeld to spelaeoid lineage from the following reasons: (a) p4 shows spelaeoid diversification model, (b) the sizes of cheek teeth fit well with those of Late Biharian $U$. deningeri, (c) $\mathrm{m} 1$ are almost identical in width/length ratio with the Late Biharian $U$. deningeri, (d) $\mathrm{m} 2$ are intermediate in trigonid width/maximal length between the Late Biharian and Early Toringian U. deningeri and (e) the general morphology and morphology of End1-c of $\mathrm{m} 1$ are similar to those of Late Biharian $U$. deningeri. We consider these bear as some of the earliest spelaeoid bears together with those from Cal Guardiola (Spain; Madurell-Malapeira et al. 2009) or Honce (Slovakia; Wagner \& Sabol 2007).

\section{Concluding remarks}

The molecular data (e.g. Krause et al. 2008) suggest that divergence between the ursid arctoid and spelaeoid lineages occured around $2.75 \mathrm{Ma}$ (but see also Loreille et al. 2001). Similarly to other cases, the phylogenetic signal of deep divergences is rather indistinct in the direct fossil record and the FADs of the phenotypically distinct representatives of the respective lineages are obviously much younger. In the case of the spelaeoid clade, this is associated with the period around the major transition in the Quaternary paleoclimatic regime, the Middle Pleistocene Revolution (Head \& Gibbard 2005 and references therein). Mudelsee \& Stattegger (1997) define 2 main phases during the Early-Middle Pleistocene transition: (1) ca 940-890 ka - increase of global ice volume with persistence of 41-ka glacial-integlacial cyclicity and (b) ca 725-650 ka - beginning of 100-ka cyclicity with high amplitude. Mudelsee \& Schulz (1997) specify that 100-ka cyclicity starts after $650 \mathrm{ka}$ ( $c a$ OIS 16). Maslin \& Ridgwell (2005) define more complicated model for Early-Middle Pleistocene transition. According to them the first two 100-ka cycles occur already in Early Pleistocene (OIS 23-20), while the subsequent period (OIS 19-16) show rather 41-ka pattern. There is an agreement that general rearrangement of system starts approximately since $0.9 \mathrm{Ma}$ (if not earlier) and was connected with deterioration of environmental conditions during the glacials. This transition, traditionally called in paleontology as end-Villafrancian event (cf. Azzaroli 1983, Palombo \& Valli 2005) or Epivillafranchian ( $c f$. Kahlke 2006, 2009), represents an important period of transformation of European large mammals assemblages. The main 
transformation of large mammals communities, supposedly including the bears, appeared between $0.9-0.75 \mathrm{Ma}$ (op. cit. and references therein) but it is well documented mostly by the Mediterranean fossil record. Horáček \& Ložek (1988, Horáček et al. 2004, Horáček 2008) demonstrate that main rearrangement of small mammals communities (constitution of specialized glacial and interglacial assemblages) takes place in Central Europe around the Biharain/Toringian boundary ( $c a$ OIS 16).

From this perspective, the evolution of cave bear lineage could be interpreted as a result of selective pressure of starting environmental deterioration. In this model, the main selective pressure would be concerned on the prolongation of hibernation period and the other specialization (e.g. dominancy of herbivory, life strategy connected with caves etc.) would be its consequences. But, if our determination of bears from Untermaßfeld as representative of spelaeoid lineage is correct, the spelaeoid lineage is already constituted before the main environmental changes and evinces fully spelaeoid lify style (bear caves) at least since the very begging of early Middle Pleistocene (but probably earlier if the bears from Vallonet cave are also spelaeoid; see Moullé 1992, Baryshnikov 2007, Argant 2009). It is therefore possible that the principal change constituting the spelaeoid lineage is connected with switching to herbivory diet and/or with changing of mating system (some authors, e.g. Baryshnikov 2007, suppose that Late Pleistocene cave bears lived in small groups). The relatively strong sexual dimorphism as well as intensive phenetic changes throughout the whole lineage could indirectly support the presence of different mating system than in $U$. arctos (limited mobility during glacials could play also an important role). Such adaptations, present since the beginning of spelaeoid lineage, can become useful exaptations after the climate deterioration.

Concerning the origin of spelaeoid lineage we conditionally accept the Kurtén's model (1968) supposing that the spelaeoid lineage is an autochtonous European descendent of $U$. etruscus and the arctoid lineage represents the descendent of Asiatic etruscus-like bears. There are justified doubts about conspecifity of the etruscus-like bears in Europe and East Asia ( $c f$. Kurtén 1968, Qiu 2006). We find some similarities, especially in $\mathrm{m} 1$, between $U$. e. etruscus and early $U$. deningeri, but these results need to be confirmed also by cranial and postcranial characters. Mazza \& Rustioni (1992) assume rather carnivorous specialization for $U$. etruscus. This is not necessary in contradiction with previous opinion. Mazza \& Rustioni (1992) based their results mostly on Italian material and it is possible that there are different tendency in the population northern and southern from Alps. Moreover the slender arrangement of $\mathrm{m} 1$ in early $U$. deningeri shows similarity even with the Italian specimens of $U$. etruscus. Based on the above, we assume that it is not possible to accept the morphometric characteristic of European U. e. etruscus (most of material originates from southern Europe) as plesiomorphic/ancestral in respect to $U$. arctos and only with limited validity to $U$. deningeri.

We find no evidence supporting the opinion of Mazza \& Rustioni (1994) that the spelaeoid lineage is derived from Ursus gr. arctos. On the other hand it is necessary to note that the early history of arctoid bears is poorly known and we have only limited knowledge about phenotypic characteristic of its early representatives. So the lack of similarities can be only a result of the lack of fossil evidence. The morphometric characteristic of pre-Toringian arctoid bears is almost unknown. The only exception could be represented by the bears from Deutsch-Altenburg 4B. Rabeder et al. (2010) give evidence that these bears belong to the arctoid lineage. We agree, based on the personal revision of the dental material, that these bears (if material is monospecific) are more similar to arctoid than early deningeroid bears. But their exact taxonomical and evolutionary position needs to be confirmed by the further material. If they are the members of the early arctoid bears, they could date the early/first migration of this lineage in Europe in the Early Biharian ( $c$ a $1.2 \mathrm{Ma}$ ).

Nevertheless, despite of serious increase of knowledge on the Late Cenozoic evolution of bears in Europe during the recent years (including the hypotheses presented in frame of this paper), it is clear that the available record is still quite fragmentary and the essential points of the above mentioned hypotheses lack a sufficiently robust empirical support. To fill the gap remains a task for further studies.

\section{Acknowledgements}

We would like to express our thanks to Ivan Horáček and Oldřich Fejfar (both from Charles University, Prague) for support during our work, the inspiring discussion and valuable comments on the topic. We are also indebted to Gennady Baryshnikov (Zoological Institute RAS, St. Petersburg), Gernot Rabeder and Matina Pacher (both from Univeristy of Vienna) and Lutz Maul (Forschungsinstitut und Naturmuseum Senckenberg - Forschungsstation für Quartärpaläontologie, Weimar) for the inspiring discussion and valuable comments on our work. We are also very grateful to the Alain Argant (LAMPEA UMR 6636-CNRS, Institut Dolomieu, Grenoble) and the anonymous reviewer for their critical reading and helpful comments on the manuscript. We are indebted to Boris Ekrt (National Museum, Prague), Adam Nadachowski and Grzegorz Lipecki (Polish Academy of Science, Kraków), Ralf-Dietrich Kahlke (Forschungsinstitut und Naturmuseum Senckenberg - Forschungsstation für Quartärpaläontologie, Weimar), Mihály Gasparik and Eszter Hankó (Hungarian Museum of Natural History, Budapest), Dieter Schreiber (Staatliches Museum für Naturkunde, Karlsruhe), Brigitte Hilpert (Friedrich-Alexander-Universität, Erlangen), Gennady Baryshnikov (Zoological Institute RAS, St. Petersburg), Đuro Huber (University of Zagreb), Evangelia Tsoukala 
(University of Thessaloniki), Barbara Herzig and Frank Zachos (Naturhistorisches Museum Wien), László Kordos (Geological Institute of Hungary, Budapest), Andy Currant (Natural History Museum, London), Reinhard Ziegler and Thomas Rathgeber (Staatliches Museum für Naturkunde, Stuttgart), Gernot Rabeder (University of Vienna), Ursula Göhlich (Naturhistorisches Museum Wien), Herbert Lutz (Naturhistorisches Museum Mainz), Madelaine Böhme (University of Tübingen), Elisabetta Cioppi and Paul Mazza (University of Florence, Florence) for the access to the collections and providing us the material in their care. The study was supported by project MKČR DF12P01OVV021 and partly by SYNTHESYS Project No. GB-TAF-3707, the Academic Project of the Institute of Geology in Prague No. AV0Z30130516, and grant No. GA205/09/0184 from the Grant Agency of the Czech Republic.

\section{References}

Ambros, D., Hilpert, B. \& KaUlich, B. 2005. Windloch bei Sackdilling. Location, history of research, geology, paleontology and archaeology. Abhandlungen der Naturhistorische Gesellschaft zu Nürnberg 45, 365-382.

ANDREWS, C.W. 1922. Note on a bear (Ursus savini, n. sp.). Annals and Magazine of Natural History, Series 9 9, 204-207. DOI 10.1080/00222932208632660

Argant, A. 1980. Une brèche fossilifère du Pléistocène moyen de Saône-et-Loire: étude paléontologique du gisement de Château. 144 pp. Université Claude Bernard - Lyon I. Lyon.

ARgAnT, A. 1991. Carnivores Quaternaires de Bourgogne. Documents des Laboratoires de géologie Lyon 115, 1-301.

ARGANT, A. 2009. Biochronologie et grands mammifères au Pléistocène moyen et supérieur en Europe Occidentale: l'apport des Canidés, des Ursidés et des Carnivores en général. Quaternaire 20, 467-480.

Argant, A. \& CréGut-Bonnoure, E. 1996. III. Famille des Ursidae, 167-179. In GUÉRIN, C. \& PATOU-MATHIS, M. (eds) Les Grands mammifères plio-pléistocènes d'Europe. Masson, Paris.

AZZAROLI, A. 1983. Quaternary mammals and the "End-Villafranchian" dispersal event - a turning point in the history of Eurasia. Palaeogeography, Palaeoclimatology, Palaeoecology 44, 117-139. DOI 10.1016/0031-0182(83)90008-1

BARYSHNIKOV, G. 1998. Cave bear from the Paleolithic of the Greater Caucasus. Illinois State Museum Scientific Papers 27, 69-118.

BARYSHNIKOV, G. 2006. Morphometrical variability of cheek teeth in cave bears. Scientific Annals, School of Geology Aristotle University of Thessaloniki 98, 81-102.

BARYSHNIKOV, G.F. 2007. Fauna of Russia and neighbouring countries. Mammals. Ursidae. 541 pp. Nauka, Saint Petersburg.

BARYSHNIKOV, G.F. 2010. Middle Pleistocene Ursus thibetanus (Mammalia, Carnivora) from Kudaro caves in the Caucasus. Proceedings of the Zoological Institute of RAS 314, 67-79.

BARYSHNIKOV, G. \& FORONOVA, I. 2001. Pleistocene small cave bear (Ursus rossicus) from the South Siberia, Russia. Cadernos Laboratorio Xeolóxico de Laxe 26, 373-398.
Baryshnikov, G. \& KalmyKov, N. 2005. Middle Pleistocene Cave Bear (Ursus deningeri von Reichenau) from Transbaikalia (Russia). Mitteilungen der Kommission für Quartärforschung der Österreichischen Akademie der Wissenschaften 14, 13-16.

BARYShNiKov, G., GermonPRÉ, M. \& SABlin, M. 2003. Sexual dimorphism and morphometric variability of cheek teeth of the cave bear (Ursus spelaeus). Belgian Journal of Zoology 133(2), 111-119.

BISHOP, M.J. 1982. The Mammal Fauna of the Early Middle Pleistocene Cavern Infill Site of Westbury-Sub-Mendip, Somerset. Special Papers in Paleontology 28, 1-108.

CRÉGUT-Bonnoure, E. 1996. A review of small Middle Pleistocene bears from France. Acta Zoologica Cracoviensia 39, 89-101.

EHRENBERG, K. 1928. Ursus deningeri v. Reich. und Ursus spelaeus Rosenm. Anzeiger der Österreichische Akademie der Wissenschaften, Mathematisch-naturwissenschaftliche Klasse 10, 96-98.

ERDBRINK, D.P. 1953. A review of fossil and recent bears of the world with remarks on their phylogeny based upon their dentition. 2 vols. 597 pp. Drukkerij Jan de Lange, Deventer.

FEJFAR, O. 1956. První dva nálezy primáta rodu Macaca Lacépéde, 1799 na území ČSR. Věstník Ústředního ústavu geologického 31, 243-245.

FEJFAR, O. 1964. Výzkum fosilních obratlovců ČSSR v roce 1963. Zprávy o geologických výzkumech 1963, 350-352.

FEJFAR, O. 1969. Die Nager aus den Kiesen von Süßenborn bei Weimar. Paläontologische Abhandlungen, Abteilung A 3(3-4), 761-770.

FEJFAR, O. 1993. Die Fauna aus den limnischen Ablagerungen von Přezletice bei Prag und ihre biochronologische Aussage. Jahrbuch des Römisch-Germanischen Zentralmuseums Mainz 40, 103-113.

FEJFAR, O. \& HEINRICH, W.-D. 1983. Arvicoliden-Sukzession und Biostratigraphie des Oberpliozäns und Quartärs in Europa. Schriftenreihe für Geologische Wissenschaften 19/20, 61-109.

FEJFAR, O. \& HEINRICH, W.-D. 1990. Proposed biochronical division of the European continental Neogene and Quaternary based on Muroid rodents (Rodentia, Mammalia), 115-124. In FEJFAR, O, \& HEINRICH, W.-D. (eds) International Symposium Evolution, Phylogeny and Biostratigraphy of Arvicolidae (Rodentia, Mammalia). Geological Survey, Prague.

FEJFAR, O., HEINRICH, W.-D. \& LINDSAY, E.H. 1998. Updating the Neogene rodent biochronology in Europe. Mededelingen Nederlands Instituut voor Toegepaste Geowetenschappen TNO 60, 533-554.

FeJfAR, O., HorÁČEK, I., ČERMÁK, S. \& WAGNer, J. 2004. Shrnutí současného stavu poznání stáří sedimentární výplně středního patra Koněpruských jeskyní na základě studia fosilních savců. In IVANOV, M. \& ÁBELOVÁ, M. (eds) Sborník př́spěvkủ 10. kvartér 2004. Masaryk University, Brno.

FREUDENBERG, W. 1914. Die Säugetiere des älteren Quartärs von Mitteleuropa mit besonderer Berücksichtigung der Fauna von Hundsheim und Deutschaltenburg in Niederösterreich nebst Bemerkungen über verwandte Forman anderer Fundorte. Geologische und Paläontologische Abhandlungen, Neue Folge 12(4/5), 455-671. 
García, N.G. 2003. Osos y otros carnívoros de la Sierra de Atapuerca. 575 pp. Fundación Oso de Asturias, Oviedo.

GARCÍA, N.G. 2004. New results in the remains of Ursidae from Untermaßfeld: comparision with Ursus dolinensis from Atapuerca and other Early and Middle Pleistocene sites. Terra Nostra, Schriften der Alfred-Wegener-Stiftung 2004, 112-113.

GARCÍA, N. \& ARSUAGA, J.L. 2001. Ursus dolinensis: a new species of Early Pleistocene ursid from Trinchera Dolina, Atapuerca (Spain). Comptes rendus de l'Académie des sciences, Série II, Sciences de la Terre et des planètes 332, 717-725.

GIBBARD, P. \& COHEN, K.M. 2008. Global chronostratigraphical correlation table for the last 2.7 million years. Episode 31, 243-247.

GibBARD, P. \& HEAD, M.J. 2009a. The Definition of the Quaternary System/Period and the Pleistocene Series/Epoch. Quaternaire 20, 125-133.

GIBBARD, P. \& HEAD, M.J. 2009b. IUGS ratification of the Quaternary System/Period and the Pleistocene Series/Epoch with a base at 2.58 MA. Quaternaire 20, 411-412.

GRANDAL-D'ANGLADE, A. 2001. A review of the cave bear sex dimorphism. Cadernos Laboratorio Xeolóxico de Laxe 26, 399-405.

GRANDAL-D’Anglade, A. \& LÓPEZ-GonZÁlez, F. 2004. A study of the evolution of the Pleistocene cave bear by morphometric analysis of the lower carnassial. Oryctos 5, 83-94.

HEAD, M.J. \& GIBBARD, P.L. 2005. Early-Middle Pleistocen transition: an overwiew and recommendation for the defining boundary, 1-18. In HEAD, M.J. \& GIBBARD, P.L. (eds) Early-Middle Pleistocene Trasition: The Land-Ocean Evidence. Geological Society Special Publication 247.

HEINRICH, W.-D. 1990. Review of fossil arvicolids (Mammalia, Rodentia) from the Pliocene and Quaternary in the German Democratic Republic, 183-200. In FEJFAR, O. \& HEINRICH, W.-D. (eds) International Symposium Evolution, Phylogeny and Biostratigraphy of Arvicolidae (Rodentia, Mammalia). Geological Survey, Prague.

HELlER, F. 1939. Die Bärenzähne aus den Ablagerungen der ehemaligen Neckarschlinge bei Eberbach im Odenwald. Sitzungsberichte der Heidelberger Akademie der Wissenschaften, Mathematisch-naturwissenschaftliche Klasse 1938, 1-57.

HelleR, F. 1949. Ursus (Plionarctos) stehlini Kretzoi, der kleine Bär aus den altdiluvialen Sanden von Mauer-Bammental und Mainz-Wiesbaden. Sitzungsberichte der Heidelberger Akademie der Wissenschaften, Mathematisch-naturwissenschaftliche Klasse 1949, 449-508.

HELLER, F. 1956. Ein kleiner Bär (Ursus sackdillingensis n. sp.) in der cromerischen Fauna der Sackdillinger-Höhle (Oberpfalz). Neues Jahrbuch für Geologie und Paläontologie, Monatshefte 1955, 520-530.

HINTON, M.A.C. 1926. Monograph of the voles and lemmings (Microtinae) living and extinct. 488 pp. Trustees of the British Museum, London.

HORÁČEK, I. 1979. Výplně 4. sluje na Chlumu u Srbska a jejich význam pro kvartérní stratigrafii (předběžné sdělení). Český kras 4, 19-34.

HORÁČEK, I. 2008. Jak se zviřátka rozkmotřila a co z toho pošlo, 63-76. In POKORNÝ, P. \& BÁRTA, M. (eds) Něco překrásného se konči - Kolapsy v př́rodě a společnosti. Dokořán, Praha.
HoRÁČEK, I. \& LOŽEK, V. 1988. Palaeozoology and the Mid-European Quaternary past: scope of the approach and selected results. Rozpravy Československé akademie věd, Řada matematických a př́rodních věd 98, 1-102.

HORÁČEK, I., LOŽEK, V. \& FEJFAR, O. 2004. The Middle Pleistocene revolution and the Central European vertebrate and molluscs fossil record. Terra Nostra, Schriften der AlfredWegener-Stiftung 2004, 119-121.

JÁNOSSY, D. 1963. Die altpleistozäne Wirbeltierfauna von Kövesvárad bei Répáshuta (Bükk-Gebirge). Annales Historiconaturales Musei nationalis Hungarici, pars Mineralogica et Palaeontologica 55, 109-141.

KAHLKE, R.-D. 2006. Untermassfeld. A late Early Pleistocene (Epivillafranchian) fossil site near Meiningen (Thuringia, Germany) and its position in the development of the European mammal fauna. BAR International series 1578, 1-143.

KAHLKE, R.-D. 2009. Les communautés de grands mammifères du Pléistocène inférieur terminal et le concept d'un biochrone épivillafranchien. Quaternaire 20(4), 415-427.

KNAPP, M., ROHLAND, N., WEINSTOCK, J., BARYSHNIKOV, G., SHER, A., NAGEL, D., RABEDER, G., PINHASI, R., SCHMIDT, H.A. \& HofREITER, M. 2009. First DNA sequences from Asian cave bear fossils reveal deep divergences and complex phylogeographic patterns. Molecular Ecology 18, 1225-1238. DOI 10.1111/j.1365-294X.2009.04088.x

KoBY, F.-E. 1953. Note sur la main de l'Ursidé de Süssenborn. Eclogae geologicae Helvetiae 45(2), 333-335.

Krause, J., Unger, T., Noçon, A., Malaspinas, A.-S., Kolokotronis, S.-O., STILler, M., SOIBElzON, L., SPriggS, H., DEAR, P.H., BriggS, A.W., Bray, S.C.E., O'Brien, S.J., RABeder, G., MAtheus, P., CoOPer, A., SlAtKIN, M., PÄÄBO, S. \& HOFREITER, M. 2008. Mitochondrial genomes reveal an explosive radiation of extinct and extant bears near the Miocene-Pliocene boundary. BMC Evolutionary Biology 8, 220. DOI 10.1186/1471-2148-8-220.

KretzOI, M. 1938. Die Raubtiere von Gombaszög nebst einer Übersicht der Gesamtfauna. Annales Musei nationalis Hungarici, Pars Mineralogica, Geologica et Palaeontologica 31, 88-157.

KRETZOI, M. 1941.Weitere Beiträge zur Kenntnis der Fauna von Gombaszög. Annales Musei nationalis Hungarici, Pars Mineralogica, Geologica et Palaeontologica 34, 105-139.

KURTÉN, B. 1955a. Contribution to the history of a mutation during 1,000,000 years. Evolution 9, 107-118. DOI 10.2307/2405583

KURTÉN, B. 1955b. Sex dimorphism and size trends in the Cave Bear, Ursus spelaeus Rosenmüller and Heinroth. Acta Zoologica Fennica 90, 1-48.

KURTÉN, B. 1958. The bears and Hyenas of the Interglacials. Quaternaria 4, 69-81.

KURTÉN, B. 1959. On the Bears of the Holsteinian Interglacial. Stockholm Contributions in Geology 2, 73-102.

Kurtén, B. 1968. Pleistocene Mammals of Europe. 317 pp. Weidenfeld and Nicolson, London.

KuRTÉN, B. 1969. Die Carnivoren-Reste aus dem Kiesen von Süßenborn bei Weimar. Paläontologische Abhandlungen, Abteilung A 3, 735-756.

KuRTÉN, B. 1975. Fossile Reste von Hyänen und Bären (Carnivora) aus dem Travertinen von Weimar-Ehringsdorf. Abhandlungen des Zentralen Geologischen Institutes 23, 465-484. 
KurTén, B. 1976. The Cave Bear Story. Life and Death of a Vanished Animal. 163 pp. Columbia University Press, New York.

LEWIS, M., PACHER, M. \& TURNER, A. 2010. The larger Carnivora of the West Runton Freshwater Bed. Quaternary International 228, 116-135. DOI 10.1016/j.quaint.2010.06.022

LISTER, A.M. 1996. The stratigraphical interpretation of large mammal remains from the Cromer Forest-bed Formation, 25-44. In TURNER, C. (ed.) The Early Middle Pleistocene in Europe. A.A. Balkema, Rotterdam, Brookfield.

LoReille, O., ORlando, L., PATOU-MATHis, M., PhilipPe, M., TABERLET, P. \& HÄNNI, C. 2001. Ancient DNA analysis reveals divergence of the cave bear, Ursus spelaeus, and brown bear, Ursus arctos, lineage. Current Biology 11(3), 200-203. DOI 10.1016/S0960-9822(01)00046-X

Madurell-Malapeira, J., Alba, D.M. \& MoyÀ-SolÀ, S. 2009. Carnivora from the late Early Pleistocene of Cal Guardiola (Terrassa, Vallès-Penedès Basin, Catalonia, Spain). Journal of Paleontology 83, 969-974. DOI 10.1666/09-054.1

MASLIN, M.A. \& RIDGWELL, A.J. 2005. Mid-Pleistocene revolution and the "eccentricity myth", 19-34. In HEAD, M.J. \& GIBBARD, P.L. (eds) Early-Middle Pleistocene Trasition: The Land-Ocean Evidence, Geological Society Special Publication 247.

MAUL, L.C. \& PARFFIT, S.A. 2010. Micromammals from the 1995 Mammoth Excavation at West Runton, Norfolk, UK: Morphometric data, biostratigraphy and taxonomic reappraisal. Quaternary International 228, 91-115. DOI 10.1016/j.quaint.2009.01.005

Maul, L.C., HeinRICH, W.-D., PARfFit, S.A. \& PAunescu, A.-C. 2007. Comment on the correlation between magnetostratigraphy and the evolution of Microtus (Arvicolidae, Rodentia, Mammalia) during the Early and early Middle Pleistocene. Courier Forschungs-Institut Senckenberg 259, 243-263.

MAZZA, P. \& RUSTIONI, M. 1992. Morphometric revision of the Eurasian species Ursus etruscus Cuvier. Palaeontographia Italica 79, 101-146.

MAZZA, P. \& RUSTIONI, M. 1994. On the phylogeny of Eurasian bears. Palaeontographica, Abteilung A 230, 1-38.

MCWILLIAMS, B. 1967. Foosil vertebrates of the Cromer forest bed in Norwich Castle Museum. 31 pp. The City of Norwich Museum, Norwich.

MilleR, E.H., MAHONEY, S.P., KenNedy, M.L. \& KenNedy, P.K. 2009. Variation, sexual dimorphism, and allometry in molar size of the black bear. Journal of Mammalogy 90(2), 491-503. DOI 10.1644/08-MAMM-A-055.1

Moullé, P.-E. 1992. Les grands mammifères du Pleistocène inférieur de la grotte du Vallonnet (Roquebrune-Cap-Martin, Alpes-Maritimes). Etude paléontologique des Carnivores, Equidés, Suidés et Bovidés. 365 pp. Ph.D. thesis, Museum National d'Histoire Naturelle à l'Institut de Paléontologie Humaine, Paris, France.

Mudelsee, M. \& Schulz, M. 1997. The Mid-Pleistocene climate transition: onset of 100 ka cycle lags ice volume build-up by $280 \mathrm{ka}$. Earth and Planetary Science Letters 151, 215-218. DOI 10.1016/S0012-821X(97)00114-3

MudELSEe, M. \& STATTEGGER, K. 1997. Exploring the structure of the mid-Pleistocene revolution with advanced methods of time-series analysis. Geologiche Rundschau 86, 499-511. DOI $10.1007 / \mathrm{s} 005310050157$
MusIL, R. 1964. Die Braunbären aus dem Ende des letzten Glazials. Acta Musei Moraviae, Scientiae naturales 49, 83-102.

MusIL, R. 1974. Lažánky bei Tišnov - eine neue Fundstätte der Biharfauna. Acta Musei Moraviae, Scientiae naturales 59, 87-93.

MusiL, R. 1991. Die Bären von Bilzingsleben, 81-102. In Fischer, K., GUENTHER, E.W., HeINRICH, W.-D., MANIA, D., MusiL, R. \& NÖTZOLD, T. (eds) Bilzingsleben IV. Homo erectus - seine Kultur und seine Umwelt, Veröffentlichungen des Landesmuseums für Vorgeschichte in Halle 44.

MUSIL, R. 2001. Die Ursiden-Reste aus der Unterpleistozän von Untermassfeld. Monographien des Römisch-Germanischen Zentralsmuseums 40, 633-658.

NADOCHOWSKI, A. 1985. Biharian voles (Arvicolidae, Rodentia, Mammalia) from Kozi Grzbiet (Central Poland). Acta zoologica cracoviensia 29(2), 13-28.

OLIVE, F. 2006. Évolution des grands Carnivores au Plio Pléistocène en Afrique et en Europe occidentale. L'Anthropologie 110, 850-869. DOI 10.1016/j.anthro.2006.10.005

PALOMBO, M.R. \& VALLI, A.M.F. 2005. Highliting the EarlyMiddle Pleistocene transition in Italian and French largemammal faunas: similarities and faunal renewals, 263-276. In HEAD, M.J. \& GIBBARD, P.L. (eds) Early-Middle Pleistocene Trasition: The Land-Ocean Evidence, Geological Society Special Publication 247.

Palombo, M.R., SARdella, R. \& Novelli, M. 2008. Carnivora dispersal in Western Mediterranean during the last 2.6 Ma. Quaternary International 179, 176-189. DOI 10.1016/j.quaint.2007.08.029

PEI, W.C. 1934. On the Carnivora from Locality 1 of Choukutien. Palaeontologia Sinica C 8, 1-217.

PrAT, F. \& ThiBAult, C. 1976. Le Gisement de Nauterie à la Romieu (Gers). Fouilles de 1967 à 1973. Nauterie I. Mémoires du Muséum National d'Histoire Naturelle, Nouvelle série, Série C, Sciences de la Terre 35, 1-82.

PREECE, R.C. \& PARFITT, S.A. 2000. The Cromer Forest-bed Formation: new thoughts on an old problem, 1-27. In LEWIS, S.G., WhitemanN, C.A. \& PREECE, R.C. (eds) The Quaternary of Norfolk and Suffolk. Field Guide. Quaternary Research Association, London.

QIU, Z.X. 2006. Quaternary environmental changes and evolution of large mammals in North China. Vertebrata Palasiatica 44(2), 109-132.

QIU, Z.X., DENG, T. \& WANG, B.Y. 2009. First ursine bear material from Dongxiang, Gansu - Addition to the Longdan Mammalian Fauna (2). Vertebrata Palasiatica 47(4), 245-264.

RABEDER, G. 1983. Neues von Höhlenbären. Zur Morphogenetik der Backenzähne. Die Höhle 34(2), 67-85.

RABEDER, G. 1989. Modus und Geschwindigkeit der Höhlenbären-Evolution. Schriftenreihe des Vereins zur Verbreitung naturwissenschaftlicher Kenntnisse in Wien 127, 105-126.

RABEDER, G. 1999. Die Evolution des Höhlenbären-Gebisses. Mitteilung der Kommission für Quartärforschung der Österreichischen Akademie der Wissenschaften 11, 1-102.

RABEDER, G., PACHER, M. \& Withalm, G. 2010. Early Pleistocene bear remains from Deutsch-Altenburg (Lower Austria). Mitteilungen der Kommission für Quartärforschung 
der Österreichischen Akademie der Wissenschaften 17, $1-135$.

REICHENAU, W. VON 1904. Über eine neue fossile Bären-Art Ursus deningeri mihi aus den fluviatilen Sanden von Mosbach. Jahrbücher des Nassauischen Vereins für Naturkunde $57,1-11$.

REICHENAU, W. VON 1906. Beiträge zur näheren Kenntnis der Carnivoren aus den Sanden von Mauer und Mosbach. Abhandlunge der Grossherzoglich Hessischen Geologischen Landesanstalt zu Darmstadt 4, 189-313.

RODE, K. 1935. Untersuchungen über das Gebiß der Bären. Monographien zur Geologie und Palaeontologie, ser. 2 7, $1-162$.

RÜGER, L. 1928. Beiträge zur Kenntnis der altdiluvialen Fauna von Mauer a.d. Elsenz und Eberbach am Neckar. Geologische und Paläontologische Abhandlungen 16(2), 197-232.

SCHÜTT, G. 1968. Die cromzeitlichen Bären aus der Einhornhöhle bei Scharzfeld. Mitteilungen aus dem Geologischen Institut der Technischen Hochschule Hannover 7, 1-121.

SHER, A.V., WEINSTOCK, B.J., BARYSHNIKOV, G.F., DAVYDOV, S.P., BOESKOROV, G.G., ZAZHIGIN, V.S. \& NIKOLSKIY, P.A. 2011. The first record of "spelaeoid" bears in Arctic Siberia. Quaternary Science Reviews 30, 2238-2249. DOI 10.1016/j.quascirev.2010.10.016

SoERGEL, W. 1926. Der Bär von Süßenborn. Ein Beitrag zur näheren Kenntnis der diluvialen Bären. Neues Jahrbuch für Mineraloie, Geologie und Paläontologie, Abteilung B 1926, $115-156$.

STUART, A.J. 1982. Pleistocene vertebrates in the British Isles. 212 pp. Longman, London, New York.

TCHERNOV, E. \& TSOUKALA, E. 1997. Middle Pleistocene (Early Toringian) carnivore remains from northern Israel. Quaternary Research 48, 122-136. DOI 10.1006/qres.1997.1901

THENIUS, E. 1958. Über einen Kleinbären aus dem Pleistozän von Slowenien, nebst Bemerkungen zur Phylogenese der plio-pleistozänen Kleinbären. Rozprave SAZU, Razred za prirodoslovne in medicinske vede 4, 631-646.

THENIUS, E. 1965. Die Carnivoren-Reste aus dem Altpleistozän von Voigtstedt bei Sangerhausen in Thüringen. Paläontologische Abhandlungen, Abteilung A 2(2/3), 539-564.

Torres, T. 1988a. Osos (Mammalia, Carnivora, Ursidae) del Pleistoceno Ibérico (Ursus deningeri Von Reichenau, Ursus spelaeus Rosenmüller-Heinroth, Ursus arctos Linneo): V. Dentivió decidual, fórmula dentaria y dentición superior. Boletín Geológico y Minero 99(5), 660-714.

TORRES, T. 1988b. Osos (Mammalia, Carnivora, Ursidae) del
Pleistoceno Ibérico: VI. Dentición inferior. Boletín Geológico y Minero 99(6), 52-106.

TORRES, T. 1992. The European descendants of Ursus etruscus C. Cuvier (Mammalia, Carnivora, Ursidae). Boletín Geológico y Minero 103, 12-22.

TORRES, T. \& CERVERA, J. 1995. Multivariate Analysis of the dental morphology of Plio-Pleistocene Ursids, with some observations concerning the phylogenetic position of Ursus deningeri Von Reichenau from Cueva Mayor (Sima de los Huesos, Atapuerca), 123-135. In Bermudez DE CASTRO, J.M., ARsuAgA, J.L. \& CARBONELl, E. (eds) Human Evolution in Europe and the Atapuerca Evidence.

WAGNER, J. 2004. A taxonomic revision of bears from selected Biharian localities of the Czech Republic. A preliminary report: I. C 718, Chlum I, Chlum IV. Cahiers scientifiques $d u$ Muséum de Lyon, Hors série 2, 139-144.

WAGNER, J. 2005a. A taxonomic revision of bears from selected Biharian localities of the Czech Republic. A preliminary report. II. Koněprusy caves - an old collection. Bulletin de la Société d'Histoire Naturelle de Toulouse et de Midi-Pyrénées $141,51-54$.

WAGNER, J. 2005b. Morfometrická charakteristika dentálního materiálu medvědů z jeskyně „Za Hájovnou“, Javořičský kras. Př́rodovědné studie Muzea Prostějovska 8, 109-142.

WAGNER, J. 2010. Pliocene to early Middle Pleistocene ursine bears in Europe: a taxonomic overview. Journal of the $\mathrm{Na}$ tional Museum (Prague), Natural History Series 179(20), $197-215$.

WAGNER, J. \& SABOL, M. 2007. Remarks on Biharian bears (Ursidae: Ursus) from the territory of Slovakia. Scripta Facultatis scientiarum naturalium Universitatis Masarykianae Brunensis 35, 159-164.

WAGNER, J., ČERMÁK, S. \& HORÁČEK, I. 2012. The presence of Ursus ex gr. minimus-thibetanus in the Late Villányian and its position among the Pliocene and Pleistocene black bears in Europe, 39-58. In ARgant, A. \& ARGAnT, J. (coord.) Proceedings of the $16^{\text {th }}$ International Cave Bear and Lion Symposium, Azé (Saône-et-Loire, France), 22-26 septembre 2010. Quaternaire, Hors-série 2011, 4.

WEST, R.G. 1980. The pre-glacial Pleistocene of the Norfolok and Suffolk coasts. 203 pp. Cambridge University Press, Cambridge, London, New York, New Rochelle, Melbourne, Sydney.

WisZniowsKA, T. 1989. Middle Pleistocene Carnivora (Mammalia) from Kozi Grzbiet in the Swietokrzyskie Mts., Poland. Acta Zoologica Cracoviensia 32, 589-630. 


\section{Appendix 1: Morphotypes definition}

\section{p4 inf.}

Character I: presence of Med and Pad

State 0: Med and Pad are both absent or present (either both or one of them) only as a very slight swellings.

State 1: only Pad is present (Med can be present as a very slight swellings).

State 2: only Med is present.

State 3: well developed Med, Pad is present as a very weak cusp or swelling.

State 4: both Med and Pad are present as obvious cusps, sometimes relatively small (Med is sometimes less evident than Pad).

Character II: characteristic of Med position

State 0: neither Med nor linguo-distal crest is present.

State 1: Med is absent (or present only as a swelling), linguo-distal crest is present.

State 2: Med is distally behind Prd, usually connected with linguo-distal crest (that could be considerably weak or short).

State 3: Med is placed medially or mediodistally from Prd, linguo-distal crest is absent (sometimes there is a chain of small cusps going from Med around the basis of Prd but not distally).

State 4: Med is placed medially with respect to Prd, linguo-distal crest is present but not in connection with Med.

\section{m1 inf.}

Character I: width of Pad-complex

State 0: Pad-c is considerably narrower than trigonid.

State 1: Pad-c is only slightly narrower than trigonid.

State 2: intermediate state between 1 and 3.

State 3: Pad-c is approximately of the same width as trigonid.

Character II: characteristic of Med-complex/Pad-complex boundary

State 0: Med-c and Pad-c are not in contact and are separated by broadly opened notch.

State 1: intermediate state between 0 and 2.

State 2: notch between Med-c and Pad-c is partly fulfilled (usually only from one side), the notch is less deep and/or more closed than in 0.

State 3: intermediate state between 2 and 4.

State 4: Med-c and Pad-c are in tight contact, the notch is fully fulfilled (sometimes only by Med-c).

Character III: general shape of Med-complex

State 0: mesial metastylids tends to curve medially, their axis forms an obtuse angle with the axis of Med (or, in several cases, only with its mesial arm), this arrangement usually leads to the bulging of trigonid's buccal wall in the place of Med/metastylids contact.

State 1: intermediate state between 0 and 2.

State 2: axis of mesial metstylids continues in the direction of axis of Med, mesial metastylids run medially or mediolaterally.

Character IV: morphology of End-complex

State 0: mesial arm of End 2 (or exceptionally of End 1) slopes gradually to the contact with Med-c (in some cases, the arm can be divided by small cuts/wrinkles and/or be terminated by mesostylid).

State 1: End-c is constituted by 3 well developed cusps (or by 2 cusps and mesostylid), that form gradually descending crest ( $c f$. Argant 1991).

State 2: End 2 bears short mesial arm, steeply terminated in the contact with mesostylid (or, exceptionally, with secondary cusp of End 2), which is in tight contact with Med-c; compared to the state 1, the edge constitutes by End-c does nor build up the gradually descending crest.

State 3: End 2 bears short mesial arm, steeply terminated in the tight contact with Med-c.

State 4: End-c arrangement is as in 2 or 3 but instead of tight contact with the wall of the Med-c, End-c is in contact only with some small secondary structure of Med-c; as a result of it, the notch between End-c and Med-c is broadly opened.

Character V: morphology of End 2

State 0: End 2 is absent.

State 1: End 2 is constituted by 1 cusp (without any mesostylid).

State 2: End 2 is constituted by 2 or more cusps or/and bears a mesostylid.

m2 inf.

Character I: central constriction

State 0: without constriction.

State 1: constriction is very weak and present only on the lingual or buccal side. 
State 2: well developed constriction is present, but only on one side (usually on the buccal one).

State 3: constriction is present on both sides, but at least on one of them is very weak.

State 4: well developed constriction is present.

Character II: mesostylid

State 0: mesostylid is absent.

State 1: mesostylid is small.

State 2: mesostylid is well developed cusp.

Character III: metalophid

State 0: neither EPrd nor EMed is present.

State 1: either EPrd or EMed only is slightly incipient.

State 2: either EPrd or EMed is present as a well distinguished cusp.

State 3: both, EPrd and EMed are present as well distinguished cusps.

Character IV: mesolophid ( $c f$. Rabeder 1999)

State 0: mesolophid is simple.

State 1: intermediate state between 0 and 2 .

State 2: mesolophid bears some secondary structures (crests).

State 3: only mesolophid 2 is incipient.

State 4: mesolophid 2 is present.

m3 inf.

Character I: diversification of space between Prd and Med

State 0: basis of Med is wrinkled, no other structures are present.

State 1: intermediate state between 0 and 2 .

State 2: there are individualized small cusps and swellings between the Med basis and Prd-c.

Character II: general form ( $c f$. Rabeder 1999)

State 0: general form is oval.

State 1: either buccal constriction or distal convexity is present.

State 2: both buccal constriction and distal convexity are present, but at least one of them is developed very weakly.

State 3: both buccal constriction and distal convexity are both present and well developed.

\section{P4 sup.}

Character I: shape of buccal wall

State 0 : buccal wall is approximately straight.

State 1: buccal wall is convex (with the maximum near the $\mathrm{Pa} / \mathrm{Me}$ boundary).

State 2: buccal constriction is only weakly present.

State 3: intermediate state between 2 and 4.

State 4: buccal constriction is strongly present.

Character II: secondary cusps of Pr

State 0 : no cusps are present.

State 1: either mesial or distal secondary cusp(s) is slightly incipient.

State 2: only mesial cusp(s) is present.

State 3: only distal cusp(s) is present.

State 4: both mesial and distal cusps are present.

\section{M1 sup.}

Character I: size relation of metastyle and parastyle

State 0: parastyle and metastyle are approximately of the same size.

State 1: parastyle is slightly larger than metastyle.

State 2: parastyle is markedly larger than metastyle.

State 3: parastyle is smaller than metastyle.

Character II: lingual constriction

State 0: lingual constriction is absent, the lingual margin is straight.

State 1: intermediate state between 0 and 2 . 
State 2: lingual constriction is weak.

State 3: intermediate state between 2 and 4.

State 4: lingual constriction is strongly developed.

\section{M2 sup.}

Character I: state of metastyle development

State 0: metastyle is absent.

State 1: metastyle is only incipient.

State 2: metastyle is a small cusp.

State 3: metastyle is a medium to large size cusp.

Character II: state of posthypocon development

State 0: PHy is absent (or indistiguishable from other secondary cusps distally behind Hy).

State 1: PHy is well developed but situated very distally, almost on the linguo-distal corner of the tooth.

State 2: PHy is only very weakly developed.

State 3: PHy is well developed as distinct cusp.

Character III: state of metaloph development

State 0: metaloph is absent.

State 1: cusp between Me and Hy/Pa are only slightly strengthened.

State 2: intermediate state between 1 and 3 .

State 3: metaloph is well evident and strong.

Character IV: characteristic of Pr-c/Hy boundary

State 0: both, Pr-c and Hy (in several cases only Hy-c) turn medially and form an acute angle.

State 1: Pr-c continues into Hy by uninterrupted arc, no angle is formed.

State 2: Pr-c/Hy boundary is approximately straight (straight or only slightly curved is also Pr-c itself).

State 3: acute angle is formed by the elements inside of $\mathrm{Pr}-\mathrm{c}, \mathrm{Pr}-\mathrm{c} / \mathrm{Hy}$ boundary is straight or curved.

State 4: axis of Hy and Pr-c are approximately parallel, but Pr-c is laterally moved with respect to Hy.

\section{Appendix 2: Results of descriptive statistic}

The Appendix 2 is available online on www.geology.cz/bulletin, together with the online version of the paper. 


\section{Appendix 3}

Table 1. Standardized Canonical Discriminant Function Coefficients for particular tooth types.

\begin{tabular}{|c|c|c|c|c|c|}
\hline p4 inf. & function 1 & m1 inf & function 1 & m2 inf & function 1 \\
\hline Intercept & 0.00000 & Intercept & 0.00000 & Intercept & 0.00000 \\
\hline CHI & 0.48162 & $\mathrm{CHI}$ & -0.13339 & CHI & 0.08364 \\
\hline CHII & -1.00149 & chIII & -0.24761 & chIII & 0.17996 \\
\hline MAXL & -2.34482 & CHIII & -0.55599 & CHIII & -0.02497 \\
\hline MAXW & 1.71133 & CHIV & -0.43864 & CHIV & 0.31465 \\
\hline MAXW/MAXL & -1.20422 & $\mathrm{CHV}$ & -0.48413 & MAXL & 3.96803 \\
\hline Eigenvalue & 0.63325 & MAXL & 6.33944 & BLTR & -0.91480 \\
\hline \multirow[t]{3}{*}{ Cum. Prop. } & 1.00000 & BLTR & -6.17336 & LLTR & -0.54889 \\
\hline & & LLTR & 0.68474 & BLTA & -1.01865 \\
\hline & & BLTA & -0.52344 & BLTA & -0.30797 \\
\hline m3 inf & function 1 & BLTA & 2.60840 & LE1 & -0.58512 \\
\hline Intercept & 0.00000 & LE1 & 0.24682 & LE2 & 0.95763 \\
\hline $\mathrm{CHI}$ & 0.38418 & LE2 & -1.16519 & WTR & -1.46445 \\
\hline CHII & 0.45507 & WTR & -0.41656 & WTA & 0,46261 \\
\hline MAXL & 1.81091 & WTA & -1.98076 & WCON & -0.39315 \\
\hline bltrml & 0.98516 & WCON & 0.03030 & WCON/MAXL & -0.03238 \\
\hline WTR & -1.63917 & WTR/MAXL & 0.79065 & WTR/MAXL & 0.78036 \\
\hline BLTR/MAXL & -0.79395 & WTA/WTR & 0.77201 & LE2/LE1 & -1.21342 \\
\hline WTR/MAXL & 2.12498 & LLTR/MAXL & 1.13893 & BLTA/LLTA & 0.30932 \\
\hline Eigenvalue & 3.71689 & BLTR/MAXL & 1.62012 & Eigenvalue & 4.33145 \\
\hline \multirow[t]{3}{*}{ Cum. Prop. } & 1.00000 & LE2/LE1 & 1.64879 & Cum. Prop. & 1.00000 \\
\hline & & Eigenvalue & 8.78699 & & \\
\hline & & Cum. Prop. & 1.00000 & & \\
\hline P4 sup. & function 1 & M1 sup. & function 1 & M2 sup. & function 1 \\
\hline Intercept & 0.0000 & Intercept & 0.00000 & Intercept & 0.00000 \\
\hline $\mathrm{CHI}$ & 0.2977 & CHI & 0.11006 & $\mathrm{CHI}$ & 0.33929 \\
\hline CHII & 0.2585 & CHII & -0.36029 & chIII & -0.25046 \\
\hline MAXL & 2.0202 & MAXL & 1.49282 & CHIII & -0.42753 \\
\hline MAXW & -10.13178 & WANT & 1.72498 & CHIV & 0.21509 \\
\hline WCON & 3.6177 & WPOST & 1.48858 & MAXL & -0.93360 \\
\hline $\operatorname{lmec}$ & 1.2951 & WCON & -6.68855 & WANT & -4.30562 \\
\hline LMEC & -0.97276 & LANT & 0.94322 & WPOST & -0.82548 \\
\hline LINL & 5.3201 & LPA & -2.88368 & WCON & 3.83997 \\
\hline LME/LMEC & -0.78471 & LPOST & -0.24381 & BLTR & 1.72831 \\
\hline MAXW/MAXL & 5.6002 & LME & 2.74172 & LLTR & 2.07883 \\
\hline LINL/MAXL & -5.02156 & IND1 & 0.13893 & BLTA & 1.89730 \\
\hline WCON/LINL & -1.68396 & WCON/MAXL & 4.13750 & LPA & -0.99010 \\
\hline Eigenvalue & 2.5751 & WANR/MAXL & 2.48020 & LPAC & -4.13865 \\
\hline \multirow[t]{10}{*}{ Cum. Prop. } & 1.0000 & WPOST/MAXL & -3.83435 & LME & 0.05457 \\
\hline & & LME/MAXL & -1.430918 & LMEC & 0.36336 \\
\hline & & LPA/MAXL & 1.11385 & LLTR/MAXL & -1.6479 \\
\hline & & WANT/WPOST & -2.66705 & BLTA/MAXL & -3.20692 \\
\hline & & Eigenvalue & 2.46281 & WANT/MAXL & 3.46202 \\
\hline & & Cum. Prop. & 1.00000 & WCON/MAXL & -3.48606 \\
\hline & & & & LPA/LPAC & 0.72593 \\
\hline & & & & LPA/BLTR & 3.37847 \\
\hline & & & & Eigenvalue & 6.17933 \\
\hline & & & & Cum. Prop. & 1.00000 \\
\hline
\end{tabular}


Table 2. Results of Mann-Whitney U Test for particular tooth types. $\mathrm{z}$ - standardized value of $\mathrm{U}$ statistic $(\mathrm{z}=(\mathrm{U}-\mathrm{m}) / \mathrm{S}$, where $\mathrm{m}$ is aritmetic mean and $\mathrm{S}$ standard deviation).

\begin{tabular}{lcc}
\hline p4 inf. & $\mathrm{z}$ & $\mathrm{p}$-level \\
\hline CHI & -1.77351 & 0.076145 \\
CHII & -2.27612 & 0.022839 \\
MAXL & -4.87535 & 0.000001 \\
MAXW & -5.10871 & 0.000000 \\
MAXW/MAXL & -1.69812 & 0.089487 \\
\hline
\end{tabular}

\begin{tabular}{lrc}
\hline $\mathbf{m} 1$ inf & $\mathrm{z}$ & $\mathrm{p}$-level \\
\hline CHI & 4.31535 & 0.000016 \\
chIII & 3.95268 & 0.000077 \\
CHIII & 5.35038 & 0.000000 \\
CHIV & 5.81900 & 0.000000 \\
CHV & -3.22734 & 0.001250 \\
MAXL & -7.22485 & 0.000000 \\
BLTR & -6.76846 & 0.000000 \\
LLTR & -6.14092 & 0.000000 \\
BLTA & -7.07815 & 0.000000 \\
BLTA & -6.82143 & 0.000000 \\
LE1 & 0.50122 & 0.616219 \\
LE2 & -5.78232 & 0.000000 \\
WTR & -3.73671 & 0.000186 \\
WTA & -4.74729 & 0.000002 \\
WCON & -2.91357 & 0.003573 \\
WTR/MAXL & 5.86790 & 0.000000 \\
WTA/WTR & -2.09044 & 0.036579 \\
LLTR/MAXL & 2.68945 & 0.007157 \\
BLTR/MAXL & 2.06191 & 0.039217 \\
LE2/LE1 & -5.71305 & 0.000000 \\
\hline & & \\
\hline & &
\end{tabular}

\begin{tabular}{lcc}
\hline $\mathbf{m} 2$ inf & $\mathrm{z}$ & $\mathrm{p}$-level \\
\hline CHI & -3.13303 & 0.001730 \\
chIII & -1.13972 & 0.254406 \\
CHIII & -2.81829 & 0.004828 \\
CHIV & -4.61609 & 0.000004 \\
MAXL & -7.15303 & 0.000000 \\
BLTR & -6.88121 & 0.000000 \\
LLTR & -6.70954 & 0.000000 \\
BLTA & -6.98612 & 0.000000 \\
BLTA & -6.51403 & 0.000000 \\
LE1 & -5.96563 & 0.000000 \\
LE2 & -4.10584 & 0.000040 \\
WTR & -5.74150 & 0.000000 \\
WTA & -6.67616 & 0.000000 \\
WCON & -5.16449 & 0.000000 \\
WCON/MAXL & 4.43488 & 0.000009 \\
WTR/MAXL & 4.68285 & 0.000003 \\
LE2/LE1 & 2.26513 & 0.023506 \\
BLTA/LLTA & -2.01715 & 0.043680 \\
\hline
\end{tabular}

\begin{tabular}{lcc}
\hline m3 inf & $\mathrm{z}$ & $\mathrm{p}$-level \\
\hline CHI & -3.73403 & 0.000188 \\
CHII & -5.22252 & 0.000000 \\
MAXL & -7.13046 & 0.000000 \\
bltrml & -5.52943 & 0.000000 \\
WTR & -7.30437 & 0.000000 \\
BLTR/MAXL & 3.57546 & 0.000350 \\
WTR/MAXL & 0.84911 & 0.395822 \\
\hline
\end{tabular}

\begin{tabular}{lcc}
\hline P4 sup. & $\mathrm{z}$ & $\mathrm{p}$-level \\
\hline CHI & -3.70993 & 0.000207 \\
CHII & -1.09770 & 0.272337 \\
MAXL & -6.47387 & 0.000000 \\
MAXW & -4.68761 & 0.000003 \\
WCON & -5.31650 & 0.000000 \\
lmec & -3.76806 & 0.000165 \\
LMEC & -5.26894 & 0.000000 \\
LINL & -6.09865 & 0.000000 \\
LME/LMEC & 2.40987 & 0.015959 \\
MAXW/MAXL & 4.71932 & 0.000002 \\
LINL/MAXL & 0.75573 & 0.449814 \\
WCON/LINL & 2.26189 & 0.023705 \\
\hline
\end{tabular}

\begin{tabular}{lcc}
\hline M1 sup. & $\mathrm{z}$ & $\mathrm{p}$-level \\
\hline CHI & -2.37139 & 0.017722 \\
CHII & -5.53146 & 0.000000 \\
MAXL & -7.98809 & 0.000000 \\
WANT & -6.81865 & 0.000000 \\
WPOST & -6.36988 & 0.000000 \\
WCON & -5.88943 & 0.000000 \\
LANT & -7.37301 & 0.000000 \\
LPA & -7.64227 & 0.000000 \\
LPOST & -7.07471 & 0.000000 \\
LME & -4.40058 & 0.000011 \\
IND1 & -6.16662 & 0.000000 \\
WCON/MAXL & 4.44017 & 0.000009 \\
WANR/MAXL & 1.35159 & 0.176508 \\
WPOST/MAXL & 4.81503 & 0.000001 \\
LME/MAXL & 5.55946 & 0.000000 \\
LPA/MAXL & -0.79195 & 0.428393 \\
WANT/WPOST & -4.02308 & 0.000057 \\
\hline & & \\
\hline
\end{tabular}

\begin{tabular}{lcc}
\hline M2 sup. & $\mathrm{z}$ & $\mathrm{p}$-level \\
\hline CHI & -2.37563 & 0.017520 \\
chIII & -3.03758 & 0.002385 \\
CHIII & -3.74185 & 0.000183 \\
CHIV & 0.92179 & 0.356638 \\
MAXL & -6.80518 & 0.000000 \\
WANT & -6.52679 & 0.000000 \\
WPOST & -6.76806 & 0.000000 \\
WCON & -6.54535 & 0.000000 \\
BLTR & -5.90813 & 0.000000 \\
LLTR & -5.61737 & 0.000000 \\
BLTA & -6.32263 & 0.000000 \\
LPA & -5.58025 & 0.000000 \\
LPAC & -5.49982 & 0.000000 \\
LME & -3.22318 & 0.001268 \\
LMEC & -4.67701 & 0.000003 \\
LLTR/MAXL & 3.84802 & 0.000119 \\
BLTA/MAXL & -2.62309 & 0.008714 \\
WANT/MAXL & 4.54091 & 0.000006 \\
WCON/MAXL & 4.19447 & 0.000027 \\
LPA/LPAC & -3.29742 & 0.000976 \\
LPA/BLTR & 1.26205 & 0.206931 \\
\hline & & \\
& &
\end{tabular}


m1 inf.

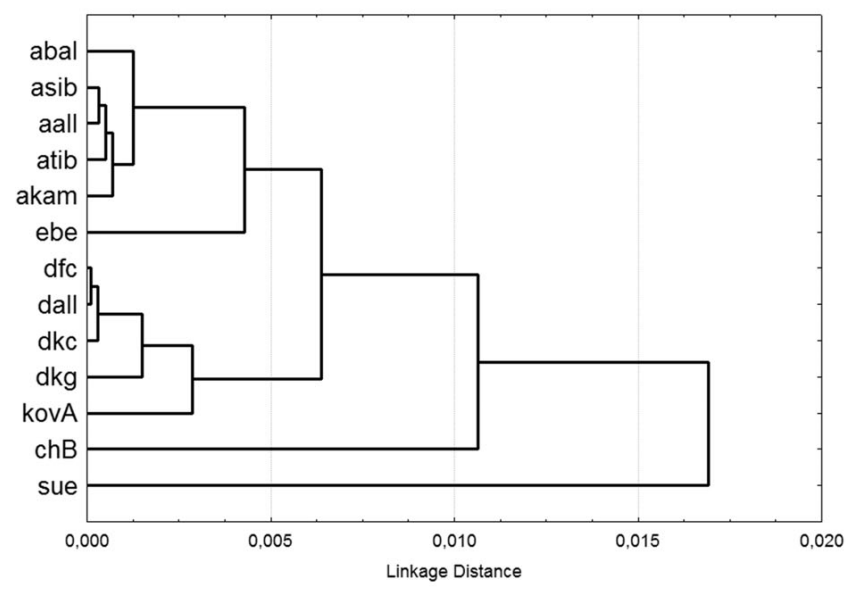

$\mathrm{m} 2$ inf.

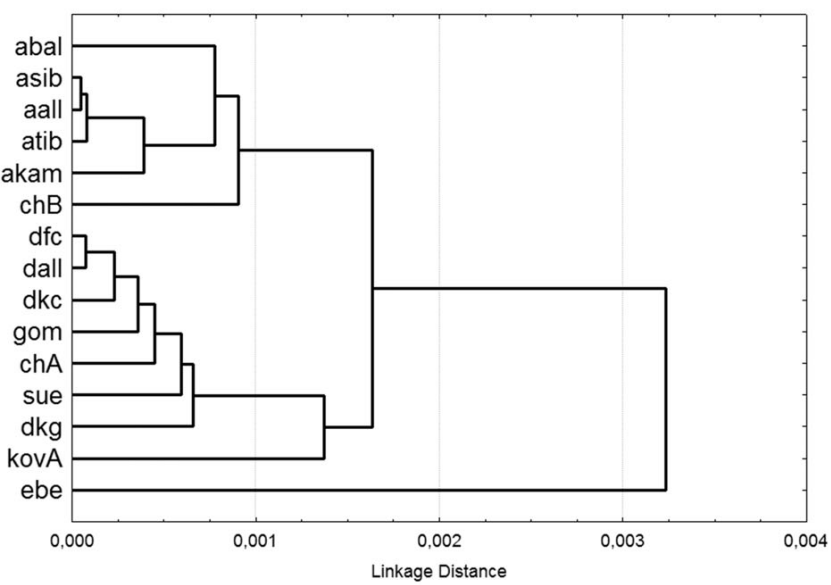

M1 sup.

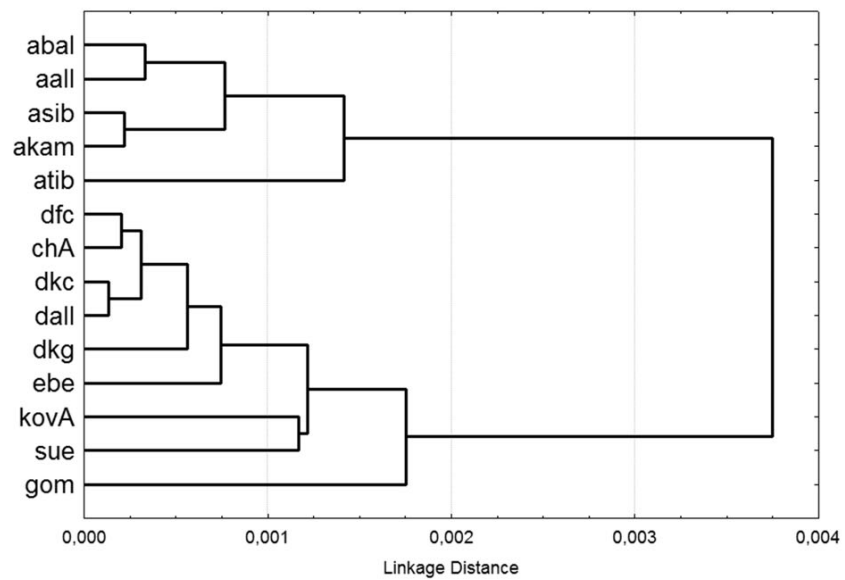

m2 inf.

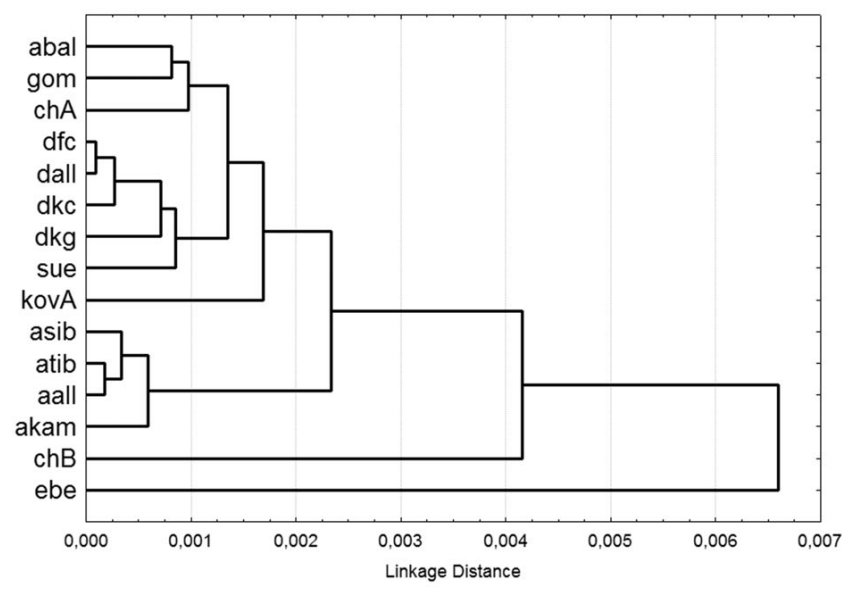

P4 sup.

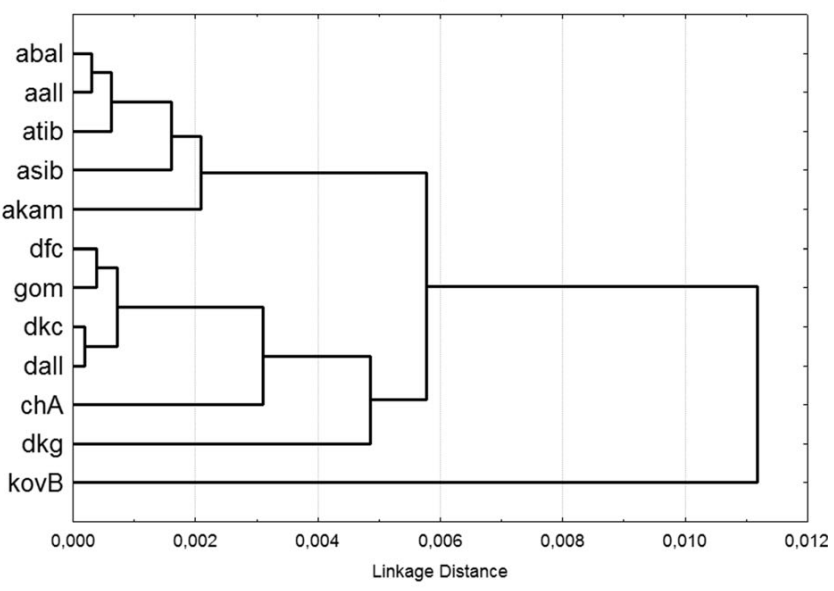

M2 sup.

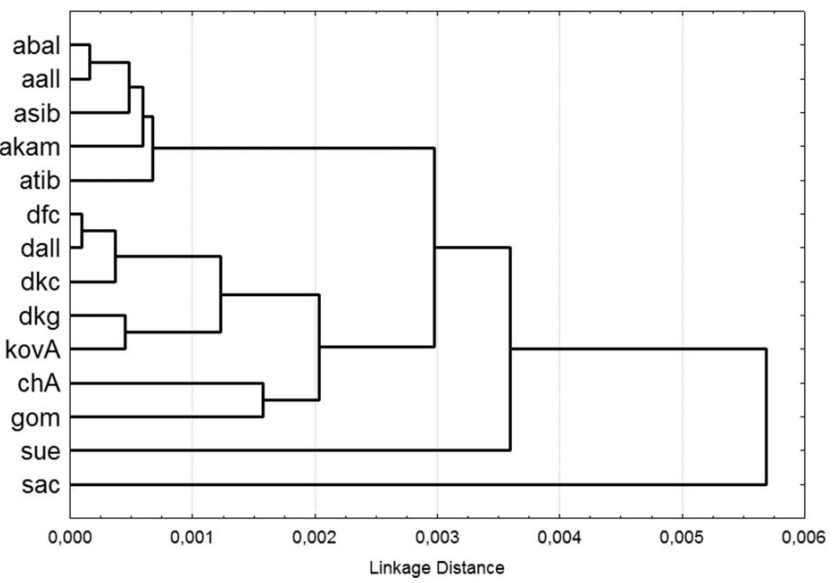

Figure 1. Results of cluster analysis. A - m1 inf., B, C - m2 inf., D - P4 sup., E - M1 sup., F - M2 sup. 